\title{
HOME DELIVERY: A FRAMEWORK FOR STRUCTURING
}

\author{
Snežana Tadić ${ }^{1}$, Miloš Veljović ${ }^{2}$ \\ 1,2 University of Belgrade, Faculty of Transport and Traffic Engineering, Vojvode Stepe 305, 11000 \\ Belgrade, Serbia
}

Received 9 September 2020; accepted 19 November 2020

\begin{abstract}
Home delivery, as a flow of goods between the company and the consumer (B2C) at the end of the supply chain ("last mile"), can be realized by the manufacturer, retailer or third party (logistics provider, crowd-worker). The growth of home delivery services in recent decades has been predominantly stimulated by the development of online ordering, i.e. e-commerce. Delivery characteristics depend on the characteristics of the environment and a number of factors related to stakeholders (customers, companies, governments). In order to improve the quality of service and customer satisfaction, company profitability and (or) reduce the negative effects of deliveries on the environment, area and community functionality, various delivery models are designed and implemented in terms of need for ordering, frequency, ordering and payment system, starting and end points, executors, reception method, security, delivery area, speed and time of realization, return flows, etc. This paper proposes a framework for a comprehensive structuring and classification of home delivery models according to the stated characteristics/criteria. Also, the advantages, disadvantages, interdependence and applicability of different delivery models in changing circumstances are described. In this way, a comprehensive review of home delivery flows was performed, the literature that deals with this area in a similar way was supplemented, but the basis for future research was also created.
\end{abstract}

Keywords: home delivery, last mile, B2C, e-commerce, characteristics, structuring, classifying, delivery models.

\section{Introduction}

Home delivery or last mile delivery is the supply chain phase that includes the activities by which goods are physically moved to the customer (Agatz et al., 2008b). Unlike traditional and "click \& collect" purchases, which are realized by the customer, and door-to-door sales, home delivery involves engaging companies in order picking/ physical preparation and delivery of ordered goods to the customer's home address or location nearby (Tadić \& Veljović, 2020d).
The organization and realization of home deliveries depend on a number of factors related to stakeholders: customers, companies and governments (Visser et al., 2014). Customers are individuals or households that require delivery of goods to a home address or other location. The size and number of household members, socio-economic characteristics, location, and degree of independence of the household in relation to the environment affect the delivery characteristics (Tadić \& Veljović, 2020a; Gardrat et al., 2016; Clarke et al., 2015;

${ }^{1}$ Corresponding author: s.tadic@sf.bg.ac.rs 
Browne et al., 2001). Households usually do not generate large flows, but given their number and territorial dispersion, they have a significant share in total flows (Tadić \& Veljović, 2020a). Companies that can be involved in the organization and realization of home delivery are divided into shippers (e-traders, traditional retailers, mail-order companies, manufacturers engaged in direct sales, etc.) and logistics providers (distribution and other logistics companies, fulfillment companies, collection and delivery points (CDPs), etc.) (Visser et al., 2014; Browne et al., 2001). Third group of stakeholders are governments at different levels (local, regional, national, international). Governments influence delivery primarily by regulations relating to goods, vehicle operation, and urban planning (Browne et al., 2001). Legal restrictions are enacted to regulate freight transport within areas (mostly urban) and generally result in more difficult or expensive last-mile delivery (Tadić et al., 2014a; Vanelslander et al., 2013). Some of the regulations most commonly applied in this area relate to vehicle carrying capacity, delivery time windows, congestion pricing and reserved infrastructure (Tadić et al., 2014a). The goals and interests of stakeholders may be in agreement, but they are often conflicting

(Zečević \& Tadić, 2006; Tadić et al., 2014b; Tadić \& Zečević, 2015b). Customers want the delivery of goods that match the quality and quantity of the ordered, at the agreed time at the desired place, at a good price. At the same time, as residents of the areas where deliveries are made, they try to reduce the negative effects of deliveries: congestion, endangering traffic safety, noise, harmful

emissions, etc. (Tadić \& Zečević, 2015b). Governments have similar goals from the aspect of social and environmental effects of deliveries. On the other hand, the high level of service required by customers and the restrictions imposed by governments contribute to the complexity of planning, organizing and realizing deliveries, and increasing the costs of companies. Their goal is to improve delivery efficiency and business profitability. One of the key instruments for achieving this goal is the consolidation of goods. Consolidation of goods can be realized through urban consolidation centers and cooperative logistics systems (Tadić et al., 2017; Conway et al., 2011), the establishment of which is usually a common interest and endeavor of companies and governments (Tadić \& Zečević, 2015a).

There are a number of potential benefits of home delivery for customers: increased satisfaction (Morganosky \& Cude, 2000), saving time and avoiding the traditional way of shopping due to crowds, specific logistical requirements of the goods, etc. (Browne et al., 2001), but also for companies and society (Cairns, 1996): making company profits, keeping community shops/spirit going, encouraging the purchase of local produce, reducing car traffic, and providing social services, which is especially important in the conditions of impossible movement, which was confirmed in the conditions of home isolation during the COVID-19 pandemic (Hobbs, 2020). On the other hand, there are numerous problems, challenges and negative economic, environmental and social effects of home delivery (Tadić \& Veljović, 2020d).

Companies apply different delivery models in terms of need for ordering, frequency, ordering and payment system, starting and end point, executors, reception method, security, delivery area, speed and time of 
realization, characteristics of return flows, etc. These characteristics are the subject of numerous scientific studies.

The characteristics that are most often analyzed in the literature and according to which classifications of delivery models are made are the end point (Tadić \& Veljović, 2020a; Iwan et al., 2016; Van Duin et al., 2016; Morganti et al., 2014b) and reception method (Fernie \& McKinnon, 2009; Agatz et al., 2008a; Punakivi, 2003; Punakivi et al., 2001), because these characteristics most directly affect customer satisfaction with the service. The speed and time of delivery have a similar significance, but also significantly less attention of researchers (Dablanc et al., 2017; Hausmann et al., 2014; Campbell \& Savelsbergh, 2006). In many studies, delivery characteristics have been analyzed according to the type of goods (Gevaers et al., 2009; Daduna \& Lenz, 2005; Browne et al., 2001), and the delivery of groceries has attracted special attention of researchers (Durand \& Gonzalez-Feliu, 2012; Campbell \& Savelsbergh, 2005; Yrjölä, 2001; Punakivi \& Saranen, 2001). In the literature, there are analyzes of home delivery from the aspect of the place and technology of order picking (Hays et al., 2005; Murphy, 2003; Kämäräinen \& Punakivi, 2002), as well as delivery executors (Park et al., 2016; Wang et al., 2016), but much less frequently from the aspect of the ordering and payment system (Morganti et al., 2014b). Return flows in home delivery have been analyzed in several papers (Tadić \& Veljović, 2020c; Bernon et al., 2016; Morganti et al., 2014b; Browne et al., 2001). The smallest number of studies deals with frequency and delivery area in terms of the degree of urbanization (Morganti et al., 2014a; Boyer et al., 2009) and coverage (local, regional, etc.) (De Koster, 2003).
Although home delivery has attracted significant researchers' attention in recent decades, structuring and classification of delivery models according to different criteria are given in a small number of papers. The Cairns' research (1996) is the first serious attempt to analyze the delivery model against different criteria (ordering system, executor, place of commissioning, method of receipt, delivery speed, etc.), but does not go into details and deals with delivery concepts that have changed significantly today in relation to the research period, especially from the aspect of the ordering system. Hübner et al. (2016) consider the characteristics of different order picking, delivery and return models in the context of simultaneous sales on a physical and online channel. De Koster (2002a), Winkenbach and Janjevic (2018), Tadić and Veljović (2020d) provided the most comprehensive structuring and (or) classification of the delivery model in terms of the number of criteria, but these studies are not detailed enough and focus more on the interrelationship of the criteria than on delivery models.

This paper proposes a framework for comprehensive structuring and classification of home delivery models in relation to different criteria. The paper deals with the physical delivery of goods from companies to customers (business to consumer-B2C). The main contribution and goal of the paper is a comprehensive structuring of home deliveries and a detailed analysis of the advantages, disadvantages and applicability of certain delivery models in different circumstances. This created the basis for future research on various aspects of home delivery.

The paper is organized as follows. After the introduction, a framework for structuring 
and classifying delivery models according to different criteria and describing the characteristics and interdependence of certain delivery models is given. After that, conclusions and directions of future research are given.

\section{Structuring and Classification of Home Delivery Models}

The characteristics of home delivery affect the level of service, level of demand and customer satisfaction, efficiency, costs and profitability of suppliers/delivery executors, as well as the environment in which these processes take place (Tadić \& Veljović, 2020d). They depend on a number of circumstances and factors related to different stakeholders (Tadić et al., 2014b), but are also interdependent. Some delivery characteristics and parameters are almost completely controlled by the supplier (e.g. picking point, return flows), and others are primarily related to the customer's decisions (e.g. end point) (Tadić \& Veljović, 2020d). By analyzing and systematizing the basic characteristics of home delivery, the criteria for their structuring can be singled out (Fig. 1). In the following, the structuring and classification of home delivery models according to different criteria will be performed and the advantages, disadvantages, interdependence and applicability of certain delivery models in different circumstances will be analyzed.

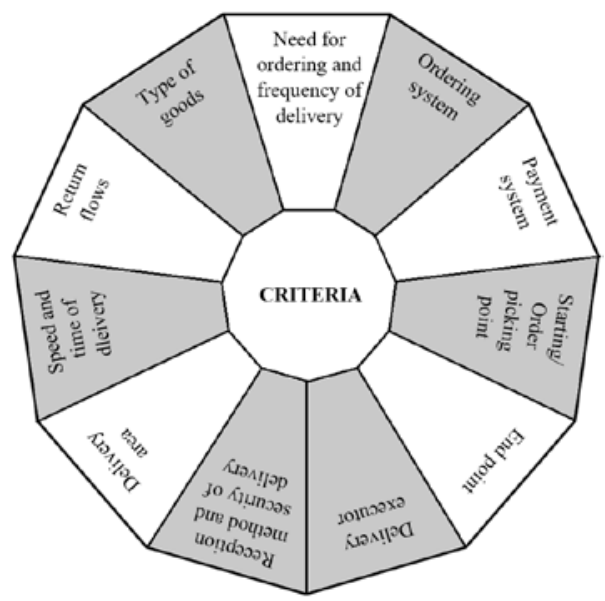

Fig. 1.

A Framework for Structuring Home Delivery

Source: (Tadić \& Veljović, 2020d)

\subsection{Need for Ordering and Frequency of Delivery}

Browne et al. (2001) consider that door-todoor sales, i.e. making goods available to potential customers in households without prior ordering, are the oldest known form of home delivery. Most research under the term home delivery involves delivery to a home address preceded by some form of personal or remote ordering. As door-to-door sales are a combination of some characteristics of 
traditional shopping (spatial and temporal connection of picking, payment and taking goods) and home delivery (goods are made available to the customer at the home address), this concept will not be analyzed in more detail in this paper. However, there are other delivery models that partially or completely exclude ordering. These models will be described below together with the delivery model that requires ordering. Fig. 2 shows the classification of the delivery model in terms of need for ordering and delivery frequency.

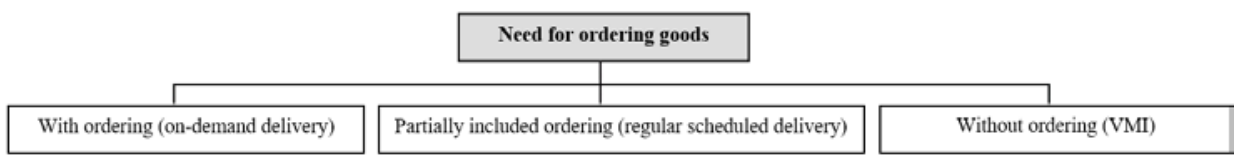

Fig. 2.

Classification of Home Delivery Models from the Aspect of Need for Ordering Goods

The classic, in practice and literature most common form of home delivery is on-demand delivery. The customer orders the goods in the store or remotely, after which the delivery is realized, which is independent of other deliveries that the supplier realizes for the same customer. The development of information and communication technologies has enabled the harmonization of the dynamics of household supply with the dynamics of consumption and customer needs. In such circumstances, supplier can provide customers with delivery "just in time" and the currently desired level of stock, but this increases the complexity of the organization of deliveries and the cost of the supplier. This delivery model is typical for durable goods, but also applies to nondurable/consumer goods (subsection 2.11).

From the supplier's point of view, regular scheduled deliveries are much more suitable for planning and organization. Regular scheduled deliveries are realized over a longer period of time according to a preagreed frequency. Companies can offer customers to permanently reserve a certain time and day of the week for delivery (Boyer et al., 2009; Kämäräinen et al., 2001a). The customer and supplier have a preliminary agreement on the frequency of delivery, but through communication technologies or during delivery, information about the next delivery (type, quantity of goods, etc.) or changing the conditions under which it is realized (time, place of delivery, etc.) can be specified. Thus, this method of delivery only partially involves ordering activities. This form of delivery has been used in the past, especially in the delivery of milk (Gould, 1998), but in recent years it has been used by supermarkets that provide grocery delivery services. Also, regular scheduled delivery may include various services (e.g. laundry and ironing). Along with regular scheduled deliveries, return flows of goods, packaging and logistics units are often realized (subsection 2.10.) (Tadić \& Veljović, 2020c). Regular scheduled delivery model enables a more efficient organization of picking and delivery of goods (Hoover et al., 2002). Also, by defining deliveries in time, the accumulation of demand, the appearance of peaks and the problems they cause can be avoided (Kämäräinen \& Punakivi, 2002) (subsection 2.9). Therefore, many companies offer customers the option of choosing this delivery model (Cristol \& Sealey, 2001). 
Home deliveries can be realized completely without ordering, i.e. the participation of the customer in defining the type and quantity of goods and the time of delivery. This model involves managing and replenishment the customer's inventory as an additional service of the supplier (vendor managed inventory - VMI) (Småros \& Holmström, 2000; Hoover et al., 2002). Replenishment of inventory can be realized on the basis of the customer's profile, i.e. historical data on the purchase, or on the basis of insight into his inventory levels. Tracking customer inventory levels can be accomplished in two ways: physical access and inventory checking or automatic tracking. Physical access to the customer's stocks can be realized in the same way as during deliveries with access to household facilities (subsection 2.7). On the other hand, using modern smart devices, internet of things, sensors, bar codes and other technologies, information on the level of household stocks can be automatically generated and sent to the supplier, in order to determine the frequency and size of delivery. The non-ordering delivery model combines the advantages of the previous two concepts: the first, which enables supply according to the current needs of customers, and the second, which reduces the need for ordering activities and ensures regular and reliable supply. However, there are a number of challenges and problems related to the application of this model. First of all, customers are not always ready to provide the supplier with a complete insight into the state of stock. Also, the intensity of household consumption can vary, which affects the unpredictability in delivery planning.

\subsection{Ordering System}

Home delivery involves the delivery of all goods to a home address (or other location chosen by the customer) regardless of the ordering system (Browne et al., 2001). Ordering goods for home delivery can be done in-person or remote (Fig. 3).

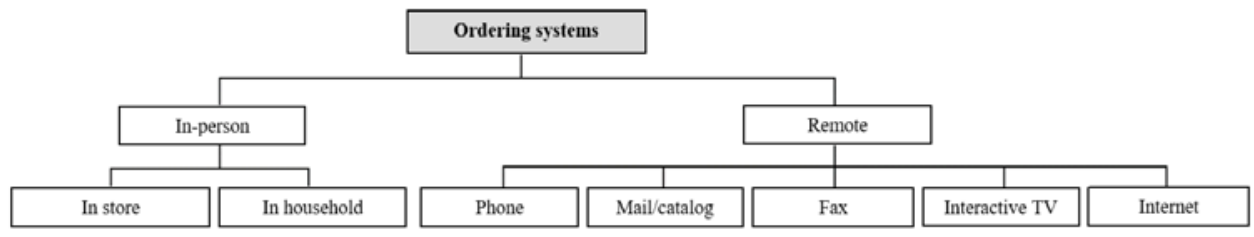

Fig. 3.

Ordering Systems in Home Delivery

In-person ordering can be done in a store or in a household. In the first case, the customer selects the goods in a store, which are then delivered to him. Such delivery is most often realized when customers are not able or do not want to transport the goods for various reasons: specific demands in terms of the scope of delivery or characteristics of the goods, inadequate means of transport, etc. (Gould, 1998; Browne et al., 2001), but they want to have a complete insight into the characteristics of the goods, which is not enabled by online sales or other forms of remote shopping. Also, the customer can select a product model in a store, which will then be manufactured or picked up from the retailer's logistics center (LC) and delivered to the home address, so that the customer would not have to visit a store again (Browne et al., 2001). In this way, 
households most often purchase furniture and large appliances (Visser et al., 2014), as well as fruits, vegetables and flowers. Inperson ordering can also be realized during traditional shopping in stores. Thus, in some cities, customers buy fresh goods (fruits, vegetables, etc.) in supermarkets, while ordering dry goods (e.g. canned products) that are delivered to them from the central LC (Cairns, 1996). Research shows that a small proportion of deliveries are generated by ordering in store (5\%; Gardrat et al., 2016). The second case implies regular scheduled delivery of goods to the home address (subsection 2.1.), when during one delivery, the realization of the next delivery (deliveries) is more precisely contracted in direct contact with the supplier. This way of ordering was more common in the past, but it is still used today.

The development of communication technologies in the twentieth century has enabled the application of various forms of remote ordering (Browne et al., 2001): ordering by telephone, fax, mail, interactive television and online ordering. The ordering location is most often household (home shopping), but it can also be any other location where the customer has access to one of the ordering systems, except for the store. The invention and the mass availability of telephones in households around the world enabled remote communication, and thus ordering. However, in parallel with the emergence and expansion of the use of telephones, there is a mass production and use of cars, as well as the opening of supermarkets and retail chains, which reduces the demand for delivery services and telephone ordering. Some delivery models also took place in such circumstances (e.g. regular scheduled deliveries of milk and deliveries of goods ordered by mail). Mail ordering has become especially important in the 1980s and 1990s (Gevaers et al., 2009). Companies send catalogs with the characteristics of goods to potential customers, who then order the goods for delivery by mail (Browne et al., 2001). This way of ordering still exists today, but it was significantly suppressed first by telephone, and then by online ordering, i.e. e-commerce. Fax and interactive TV were of less importance in ordering goods for delivery.

Home delivery is increasingly evolving with the advent of e-commerce and online ordering (Iwan et al., 2016; Morganti et al., 2014b; Gevaers et al., 2009). Most research in the field of home delivery considers the delivery of electronically ordered goods (Slabinac, 2015). Interest in electronic home shopping began in the 1970s when early videotext systems were used (Gould \& Golob, 1997). Today, ordering goods in the e-commerce system is done through the Internet, e-mail, mobile applications and in other ways. E-commerce is becoming increasingly important in the market. About $60 \%$ of customers in the EU bought online in 2018 (European Commission, 2019). In the same year, the share of e-commerce in total global retail was $12.2 \%$, and analysts expect that by 2023 it will grow by about $2 \%$ each year and thus reach $22 \%$ (eMarketer, 2019). An increasing number of e-commerce companies, and traditional retailers and companies that have received orders by phone and mail, are increasingly using the Internet as a marketing and sales channel (Browne et al., 2001). Visser et al. (2014) predict that in the future, additional growth in e-commerce will occur due to the expansion of demand to new segments of customers (e.g. old population), to reduction in the number of traditional stores, growth of e-grocery and the use of smartphones. One 
of the main disadvantages of e-commerce and other forms of remote ordering is the impossibility of direct and complete insight into the characteristics of goods ("look \& feel”) (Hübner et al., 2016; Daduna \& Lenz, 2005). Therefore, some e-retailers are opening facilities where customers can get information about the goods or test/try them, and where no sales are made (Visser et al., 2014). This practice is called "offline to online" $(\mathrm{O} 2 \mathrm{O})$.

\subsection{Payment System}

Payment for goods for delivery can be realized in different ways: online/mobile payment, using a credit card or cash payment, etc. (Fig. 4). The method of payment depends on the moment of payment (when ordering or taking goods), the ordering system, the options offered by the supplier, the customer's preference, the type and value of the goods, etc. Most retailers offer distance payment options, so customers most often use this benefit. This method of payment has been facilitated by the development of numerous mobile applications for ordering and payment. Online payment is most often made when ordering online, while cash or credit card payments are usually made when taking goods (Winkenbach \& Janjevic, 2018). Also, the goods that the customer orders in a store can be paid in cash or by credit card at the time of ordering.

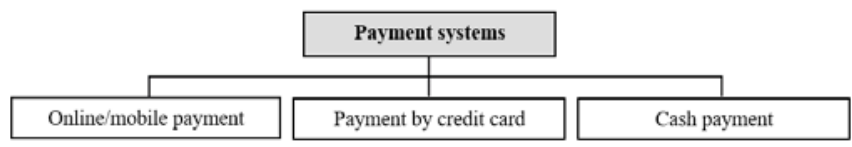

Fig. 4.

Payment Systems in Home Delivery

\subsection{Starting/Order Picking Point}

Warehousing and order picking costs are very high in traditional but also in logistics systems for home delivery, in which they have the largest share in total costs together with delivery costs (Kämäräinen et al. 2001b; Punakivi \& Tanskanen 2002; Tanskanen et al., 2002; Kämäräinen \& Punakivi, 2002; Vanelslander et al., 2013). The costs of picking a wide range of individual products in small quantities are higher than the picking costs at the pallet level (Agatz et al., 2008b; Vanelslander et al., 2013). Therefore, the way and place of order picking, i.e. the starting point of delivery is one of the most important criteria according to which home delivery models are classified. While the most common end point of delivery is specified by the name of the service, less is usually known about its starting point. Starting point of home delivery or "order penetration point" (Oldhager, 2003) is the point at which stocks are located (Lim et al., 2018) and at which the customer order activates the order fulfilment process (Fernie \& McKinnon, 2009). Picking of goods for delivery can be realized by the retailer, the retailer's supplier (wholesaler) or the manufacturer (De Koster, 2002a), and it can be manual, semi-automated or automated (Hübner et al., 2016) (Fig. 5). 


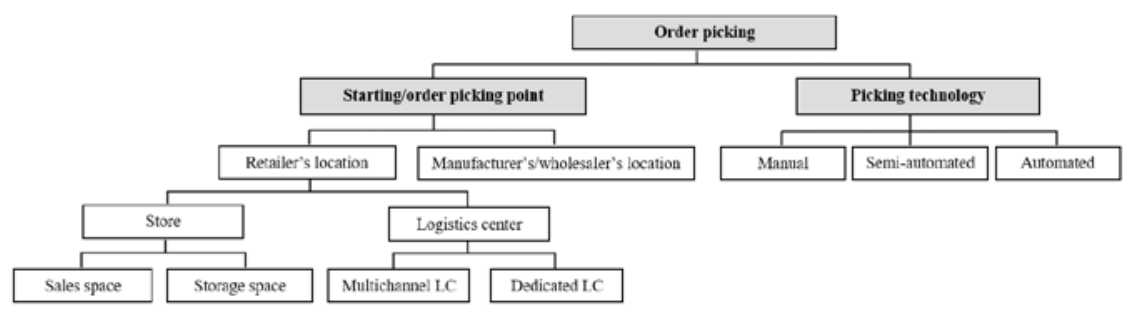

Fig. 5.

Order Picking Point and Technology in Home Delivery

The retailer can apply order picking based on stores (sales or storage space of the store), LCs (multichannel or dedicated only for deliveries) or a hybrid model (Browne et al., 2001; De Koster, 2003). The choice of order picking executor, location and technology has a significant impact on the investment required, operational efficiency, costs and level of service (Vanelslander et al., 2013; Boyer et al., 2005; Punakivi \& Tanskanen, 2002), and depends on the sales channel, the existing infrastructure, supplier's decision, levels, stability and density of demand, delivery areas, types and values of goods, etc.

Store-based order picking is the oldest model of picking goods for home delivery (Kämäräinen \& Punakivi, 2002). Picking is realized manually. It is usually used by companies that operate on both channels and have a dense network of stores (Hübner et al., 2016; Vanelslander et al., 2013), but online retailers can also use stores of thirdparty, especially in the case of low demand (De Koster, 2002b). This concept does not require additional investment costs and provides an opportunity for "click \& mortar" companies to take advantage of the full range offered by physical sales (Kämäräinen \& Punakivi, 2002), shortening the last mile by approaching the customer (Hackney et al., 2006; Lunce et al., 2006), enables higher delivery speed and specific storage conditions (e.g. active and passive cooling) (De Koster \& Neuteboom, 2001). It also allows retailers to achieve rapid geographic expansion, enabling market share and gaining customer loyalty much faster than in the case of picking at a LC (Fernie \& McKinnon, 2009). On the other hand, retailers must decide in which store they will pick the ordered goods, so as to achieve a compromise between the efficiency of picking and the distance, time and cost of delivery (Hays et al., 2005). Order picking can be realized in the sales or storage space of the store. Picking in sales space (taking off the shelf) is expensive and inefficient (Kämäräinen et al., 2001b), because it is not designed for this activity (Kämäräinen \& Punakivi, 2002; De Koster \& Neuteboom, 2001), and can disturb the functioning of stores and the standard of service for online customers, as well as for customers who make traditional purchases. Picking inefficiencies are caused primarily by inadequate locating of related goods (e.g. milk and bread are distant from each other), goods arrangement by margin rather than product turnover (eye-level products have high margins), and interference by customers (De Koster, $2002 b)$. Also, goods can be available at the time of online ordering, but then purchased from customers in the store and unavailable 
for picking by workers (Fernie \& McKinnon, 2009). In this case, online customers must be canceled or offered alternative goods, which can cause their dissatisfaction (Murphy, 2007; Fernie \& Sparks, 2004; Browne et al., 2001). This is precisely one of the risks of spatial and temporal separation of ordering and taking goods (Gardrat et al., 2016; Hübner et al., 2016). These problems can be avoided by applying picking in the storage space of the store. Nevertheless, storage space in stores has been significantly reduced or eliminated in recent decades in order to expand sales space (De Koster, 2002b).

The retailer can use same LC for picking goods for supply store and home deliveries (integrated picking, multichannel LC). This concept brings the benefits of risk pooling, reduces inventory levels, delivery times, overhead and inbound transportation costs (Hübner et al., 2016). Also, in this case, the existing infrastructure is used, which affects the lower investment costs. On the other hand, this model has a number of disadvantages (De Koster, 2002b). The warehousing, picking, sorting and packaging technologies, inventory management, information systems and operation of these LCs are adapted to the quantitative and qualitative characteristics of traditional retail requirements (larger quantities of one type of goods, deterministic requirements in terms of location and delivery time, etc.), and as such they are not suitable for the realization of $\mathrm{B} 2 \mathrm{C}$ flows. This primarily refers to the management of a wide range of products, which need to be delivered to different locations. Picking is usually semiautomated, because automatic technologies are adapted to picking at the pallet level, and additional procedures related to product units are realized manually.
In conditions of high demand and a wide range of goods, the most efficient picking solution is the establishment of a dedicated LC for deliveries (De Koster, 2002b). This model is most often used by online retailers, because they do not own stores (Vanelslander et al., 2013), but also by some “click \& mortar" retailers. Namely, with the increase in demand, picking goods in stores in parallel with traditional shopping becomes even more difficult (Murphy, 2003; Kämäräinen \& Punakivi, 2002), so in such conditions it is justified to open a dedicated LC for deliveries (Vanelslander et al., 2013). Careful monitoring of demand levels is of paramount importance, as the premature opening of a dedicated LC has resulted in the failure of many companies (Fernie \& McKinnon, 2009). Dedicated centers are designed for picking a large number of small units; provide benefits related to economies of scale and service to a larger area than stores (De Koster \& Neuteboom, 2001). High efficiency of LCs is achieved by applying appropriate warehouse technologies, sorting and information systems (De Koster, 2002b). Automated or semi-automated picking is applied in dedicated centers (Hübner et al., 2016; Kämäräinen \& Punakivi, 2002). The main advantages of automated picking are reduced labor needs and lower operating costs (Kämäräinen et al., 2001b). Another advantage of using a dedicated LC is the convenience of applying the VMI concept (subsection 2.1) (Kämäräinen \& Punakivi, 2002). On the other hand, high investments in capacity are needed, which can be underutilized due to fluctuations in demand (Kämäräinen \& Punakivi, 2002). In addition, the distances traveled and delivery costs increase, because the LC is usually further away from the customer than the stores (De Koster \& Neuteboom, 2001). 
The hybrid model of picking goods for delivery combines the use of LCs and stores. Some companies realize picking from LCs only in areas with higher demand, and other requirements are met by picking in stores (Kämäräinen \& Punakivi, 2002). Yrjölä (2001) proposes a hybrid approach to the selection of picking point depending on the type of goods.

In the past, many manufacturers and wholesalers marketed their products directly to customers, but this concept has proven difficult over time due to the high costs of marketing and advertising (Browne et al., 2001). However, with the development of e-commerce and mass customization, as well as the efforts of manufacturers to reduce distribution costs (Mukhopadhyay \& Setoputro, 2004), the place of manufacturing is increasingly the starting point of delivery (Fernie \& McKinnon, 2009). This delivery model is called drop-shipping. In this case, the customer electronically orders the goods, retailers make only the sale, and the manufacturer (or the retailer's supplier/ wholesaler) organizes the direct delivery of the goods to the customer (Gan et al., 2010; Bailey \& Rabinovich, 2005). Drop shipping brings numerous benefits to the manufacturer and customer, but also to the retailer, who does not bear the cost of keeping stock (Ma et al., 2017).

\subsection{End Point}

Home delivery is a distribution channel that ends at a home address or location nearby (Fernie \& McKinnon, 2009) (Fig. 6). The end point is usually determined by the customer (Lim et al., 2018). The final destination of goods is usually the household of the customer, but it can be done directly or indirectly. Although customers prefer direct delivery (Morganti et al., 2014b), goods are sometimes delivered to other addresses (customer's workplace, neighbor's or friend's household, etc.), CDPs, drop-off companies, and recently in the trunk of the customer's car, when the end point of delivery can be a home address or other location, depending on the movement of the car. These locations may be a targeted end point of delivery or an alternative solution after a failed home delivery. In case of unsuccessful delivery, the customer must pick up the goods at the supplier's LC (McLeod et al., 2006) or the delivery is realized again, which requires additional costs, increases the customer's waiting time and may result in failure again (Fernie \& McKinnon, 2009). Therefore, changing the end point of delivery is a good solution to improve delivery efficiency (Van Duin et al., 2016). From other addresses, CDPs or drop off companies, the goods can be delivered to the household by the customer, recipient (neighbor, drop-off company) or crowd-worker (subsection 2.6).

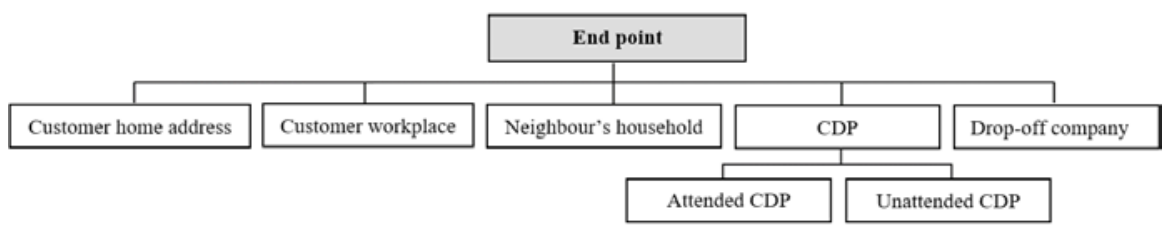

Fig. 6.

End Points of Home Delivery 
Delivery to the customer's home address is input flow of goods into the household (Tadić \& Veljović, 2020a). Despite the possibility of choosing different end points, customers still most often opt for delivery to home address (Weltevreden \& Rotem-Mindali, 2009; Morganti et al., 2014b). This model is suitable because in most cases, the use and storage of goods is realized in the household. Also, when delivering some types of goods, customers tend to reduce the number of intermediary points in order to eliminate security and privacy risks. On the other hand, delivery to home address increases the activity of vehicles in residential areas, which can have various negative effects (congestion, noise, endangered traffic safety, increased harmful emissions, etc.) (Allen et al., 2007).

The goods can be delivered to the trunk of the customer's car. Although this delivery model is analyzed in subsection 2.7 , which refers to the ways of receiving the goods, this part will also describe some of its characteristics, since the end points of delivery may be different depending on the current location of the car. Research (Reyes et al., 2017; Ozbaygin et al., 2017) shows that delivering goods to the trunk provides a significant opportunity for companies to reduce distance traveled, economic cost, harmful emissions and congestion in the last miles. Namely, based on the information obtained from the customer or tracking the movement of his car, a location significantly closer to the place of picking or end points of other deliveries than the customer's address can be chosen as the end point of delivery (Reyes et al., 2017).

Increasingly, the end point of delivery is the customer's workplace. Since deliveries are most often realized during the day, failures in delivery to the workplace are unlikely, because there is almost always someone available who can receive the goods (Weltevreden \& Rotem-Mindali, 2009). Also, the delivery of goods from workplace to the home address does not require the realization of additional trips, but the customer can do it on a regular return from work. Although more and more companies offer delivery service to the customer's workplace, very few employers have systems for receiving, storing and distributing goods to workplaces, because there are numerous challenges in terms of goods safety and system management (McKinnon \& Tallam, 2003). Also, employers may be dissatisfied if the number of deliveries and the quantity of goods become so large that they disrupt the daily activities of the company (Browne et al., 2001).

A neighbor's address can also be an end point of delivery, which is especially common after a failed delivery to a customer's address (Edwards et al., 2010b; Weltevreden \& Rotem-Mindali, 2009). According to survey results, $84 \%$ of online shoppers would allow a neighbor to receive goods on their behalf (IMRG, 2008), so companies are increasingly offering customers this option (Morganti et al., 2014b). Companies often require customers to specify the address to which they should redirect delivery in the event of their absence when ordering goods. For many customers, the absence of neighbors is one of the factors that prevent them from using delivery services (Gould, 1998). According to research (see Van Duin et al., 2016), delivery of goods to neighbors can increase delivery efficiency by up to $15 \%$. This improvement could be significantly higher if some households served as hubs for receiving, storing and eventual final delivery of all shipments ordered in a certain area 
(Tadić \& Veljović, 2020a). Some companies have already applied this concept (Cairns, 1996). In fact, in this case the household of the neighbor serves as a CDP or drop off company (McKinnon \& Tallam, 2003). These concepts will be explained below.

CDPs are receiving increasing attention both in practice and in the literature, and their number is growing, especially in Europe (Morganti et al., 2014b). For this reason, this end point will be described in detail in this paper as well. CDPs are a network of locations where suppliers/operators pool and deliver ordered goods, and customers' consignees pay, collect or return goods (Yuen et al., 2018; Piplani \& Sarasvat, 2012). These places are also called by other terms: collection points, cluster points, pick-up points, pick-own-parcel points, reception points, etc. They are most often located in busy places (transport hubs, stores, post offices, etc.), so that customers would not have to make additional trips in order to pick up the goods (Weltevreden, 2008). CDPs can be used as target or alternative end point of delivery (McKinnon \& Tallam, 2003). Post office is often an alternative end point of delivery after one or more unsuccessful delivery attempts to a home address or workplace, while other CDPs are almost always the initial end point of delivery (Weltevreden \& Rotem-Mindali, 2009). There are two variants of CDP, attended and unattended (Lim et al., 2018; Visser et al., 2014; Weltevreden, 2008; McKinnon \& Tallam, 2003).

Attended CDPs (manned CDPs, service points, parcel service points, staffed pickup points) employ persons who receive the goods and hand over them to the customer. Attended CDPs can be established by developing new infrastructure, using existing stores or collaborating with third parties (Wang et al., 2014). Building new infrastructure implies higher investments and risks. As in the case of picking points, companies operating exclusively on the online channel most often build new or use third-party facilities for CDPs, while companies operating on the physical and online channel seek to leverage existing infrastructure. Therefore, “click \& mortar" retailers often use their own stores as CDPs, relying on shop-in-shop concept (Weltevreden \& Rotem-Mindali, 2009). Third-party facilities most commonly used as CDPs are facilities with long working hours (Morganti et al., 2014b; Fernie \& McKinnon, 2009; Gevaers et al., 2009): post offices, gas stations, garages, self-storage centers, supermarkets, newsstands, bakeries, internet cafes, etc., where a special point is usually set up where customers can pick up the ordered goods (Hübner et al., 2016). Browne et al. (2001) in CDPs include workplace, and McKinnon and Tallam (2003) include all points except the customer residence. Some authors (e.g. Lim et al., 2018) in last mile delivery via CDPs include the collection of the ordered goods by the customer from the facility/store where it is picked "click \& collect"). However, this concept is not a form of home delivery, because it does not imply the involvement of supplier or a third party in the implementation of delivery process, but only the customer. Thus, store has the function of CDP for home delivery only as a place of delivery of goods that are picked at another location. The listed facilities in which CDPs can be located are usually very numerous and territorially evenly distributed, especially in urban areas, and as such suitable for CDPs, because they are close to a large number of customers. Higher demand for delivery to CDPs could contribute to an increase in sales/ revenue of the retailer in whose stores CDP is located (Weltevreden, 2008; McKinnon 
\& Tallam, 2003), which in turn could reduce commission for facility use (Wang et al., 2014).

Unattended CDPs (unmanned CDP, automated pack stations, automated parcel machines, parcel lockers) are locations where automated reception and storage of goods is performed until the moment when the customer picks it up, using the order reference code. Goods are stored in lockers or containers, based on automated warehousing and picking systems such as those in factories and warehouses for small goods (e.g. spare parts, magazines) (Daduna \& Lenz, 2005; McKinnon \& Tallam, 2003; Merz, 2002). Unattended CDPs can be stationary or mobile (Yuen et al., 2018). Stationary CDPs can be located in households or in public places: railway stations, car parks of companies, inside or next to petrol stations, supermarkets, post offices, universities (Kämäräinen \& Punakivi, 2002; McLeod et al., 2006; Weltevreden \& Rotem-Mindali, 2009). Mobile CDPs are actually automatically guided vehicles with lockers, which at the initial location receive goods and transport them to locations in the immediate vicinity of the customers (Joerss et al., 2016; DHL, 2014). Major logistics service providers in the world have implemented unattended CDPs (Zhou et al., 2020; Ghajargar et al., 2016). Unlike attended CDPs, where the collection of goods is conditioned by working hours, mobile and stationary unattended CDPs installed outside facilities allow the customer to collect the goods at any time (Zhou et al., 2020; Browne et al., 2001).

The benefits of using CDPs are numerous, from the perspective of all stakeholders (Zhou et al., 2020; Chen et al., 2018; Yuen et al., 2016; McLeod et al., 2006). From the supplier's perspective, this model minimizes the number of failed home deliveries, thus reducing costs. Also, deliveries to CDPs enable the consolidation of goods, better utilization of means of transport, reduction of vehicle-kilometers traveled and energy savings (Gevaers et al., 2009). Consolidation of transport flows to and within urban areas can lead to faster and more reliable deliveries (Visser \& Nemoto, 2003). It also reduces congestion on roads, demand for parking in residential areas, harmful emissions and improves community functioning (Chen et al., 2017; Van Duin et al., 2016). According to Edwards et al. (2010b), by applying CDPs carbon emissions can be reduced by up to $83 \%$. There are numerous benefits to using CDPs from a customer perspective as well. Delivery services to CDPs eliminate the need to wait for delivery at home (Agatz et al., 2011). Highly developed networks of CDPs, such as those owned by some companies in Germany and France, allow customers to pick up ordered goods quickly and easily (90\% of the population can reach CDPs in 10 minutes) (see Morganti et al., 2014b). Customers often cover short distances on foot or by bicycle, which is an additional benefit from a social and environmental point of view. Finally, using CDPs as an alternative delivery end point brings significant benefits. The distance traveled by the customer after a failed home delivery to pick up the goods can be reduced by $80 \%$ by using CDPs compared to the trip to the supplier's LC that is usually realized in such situations (McLeod et al., 2006).

On the other hand, there are problems and negative effects of the using and development of CDPs networks. Although using CDPs can significantly improve delivery efficiency (Punakivi \& Tanskanen, 2002), many companies that have implemented this system have failed (Fernie \& McKinnon, 
2009). Insufficient geographical coverage, i.e. a small number of CDPs in some areas is caused primarily by the desire of suppliers to independently (or by hiring a logistics provider) make a complete delivery to the customer's home address, to maintain brand image and identity and be competitive (Browne et al., 2001). Insufficient coverage can also be caused by legal restrictions. Thus, security regulations in France prohibit leaving packages unattended in automated lockers, due to the possibility of terrorism (Morganti et al., 2014b). Although an increase in the number of CDPs reduces the distance traveled by customers, it does increase the distance traveled by suppliers, as well as the cost of building or renting and maintaining facilities. Taking into account investment costs, Joerss et al. (2016) predict that deliveries to CDPs are unlikely to have a major impact on the market. On the other hand, Ghajargar et al. (2016) state that these costs can be offset by savings generated by sufficient demand and consolidation of goods. Significant implementation challenges also relate to problems with high parking demand and the potential increase in congestion in areas around CDPs (McLeod et al., 2006). Finally, there is still insufficient customer interest in such a delivery model, which can only be profitable with a sufficient level of demand and an adequate price (Kämäräinen \& Punakivi, 2004). The need to travel to CDPs significantly reduces the convenience of home shopping and is acceptable to only a small number of customers (McKinnon \& Tallam, 2003). Therefore, despite the numerous benefits of using and the developed network of CDPs in some countries (Winkenbach \& Janjevic, 2018), customers most often opt for delivery to home address (Weltevreden \& RotemMindali, 2009; Morganti et al., 2014b; Yuen et al., 2018). Some research shows that there are still prospects for mass acceptance of this solution. According to research (McLeod et al., 2006), 83\% of delivery service users would consider using CDPs. Joerss et al. (2016) note that about half of customers are willing to accept this method of delivery provided it is cheaper than delivery to home address (by \$ 3). In the future, companies must encourage customers in various ways to use this delivery model (e.g. by reducing the price for delivery to CDPs; Visser et al., 2014), in order to achieve greater profitability.

The end point of delivery can also be a local drop-off company/agent. Local drop-off and delivery is an extension of the CDPs service, because in addition to receiving, companies also deliver goods to the customer's home address (Fernie \& McKinnon, 2009; McKinnon \& Tallam, 2003). Therefore, this concept will be described in the next subsection, which refers to the delivery executors.

\subsection{Executor of Delivery}

Home deliveries also differ in relation to the executor (Fig. 7). The number and type of executors depend on the starting and end point of delivery. Direct deliveries to the home address are usually organized by one entity, and at least one other must be involved in the execution of indirect deliveries. Direct delivery to the home address and deliveries to other points can be realized by supplier: retailer, retailer's supplier (wholesaler) or manufacturer, either independently or by hiring a third party: logistics provider (Allen et al., 2007) or crowd-worker (Wang et al., 2016). Delivery of goods to the home address from other delivery end points can be realized by different entities. The customer delivers the goods delivered to the workplace or in the trunk of his own car. The neighbor 
who received the goods can also deliver it to the customer or wait for him to pick it up. From the CDP to the home address, the goods are usually delivered by the customer or crowd-worker, and drop-off companies deliver the goods they receive. A special form of delivery is humanitarian delivery, which can be realized by charitable, social and local government organizations (Cairns,
1996). It is most often provided to persons whose mobility is disabled or hindered (old, disabled, sick, persons in inaccessible rural areas with poor infrastructure, etc.), but also in conditions of limited movement due to weather disasters, pandemics, war, etc. Although this delivery has a significant social role, it will not be discussed in more detail in this paper.

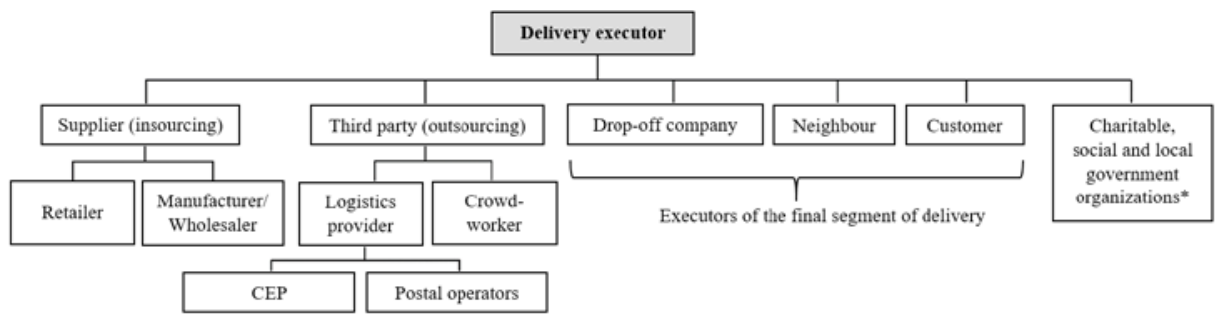

* executors of humanitarian delivery, which is not analyzed in this paper

Fig. 7.

Executors of Home Deliveries

Retailer, wholesaler or manufacturer can realize the delivery with their own resources (insourcing, in-house delivery). In that case, they must bear the investment and maintenance costs of the vehicle fleet. This model is often applied by companies that operate on the physical and online channel (Vanelslander et al., 2013) and which can use existing resources, but also many e-retailers (Winkenbach \& Janjevic, 2018). Logistic outsourcing is avoided by companies that sell goods with specific logistical demands (e.g. groceries), because traditional providers are often not able and equipped to realize the delivery of such goods (Hausmann et al., 2014). Insourcing enables complete control of companies over the organization and realization of the delivery process. Also, by branding vehicles and work uniforms of drivers, a positive promotional effect can be achieved.
However, companies are much more likely to hire logistics providers to deliver (outsourcing) (Iwan et al., 2016; Punakivi \& Saranen, 2001). These are national postal operators, global integrators, courier, express and parcel services (CEPs), general freight carriers, etc. (Morganti et al., 2014b; Daduna \& Lenz, 2005). Companies hire professional executors for logistics tasks, having in mind their experience, qualified workforce and technology, in order to reduce their own capacities, perform exclusively core business, achieve logistics efficiency, timely delivery and customer satisfaction (Langley, 2019). Also, a logistics provider usually manages large quantities of goods, consolidates goods and has a distribution network that covers a larger area, which enables a reduction in delivery costs (Visser et al., 2014; Vanelslander et al., 2013). However, many logistics providers do not provide 
home delivery services due to numerous operational problems and high costs (Tadić et al., 2015). The development of e-commerce and home delivery has significantly increased the activity of CEPs (Tadić et al., 2015; Hesse, 2002; Esser \& Kurte, 2005; Park et al., 2016). Because CEPs often have small capacities to be adequate partners for large suppliers, local CEPs often pool their capacities on brokerage platforms in order to form a flexible CEP network (Hausmann et al., 2014). Cooperation of CEPs and optimization of the distribution network contribute to solving the problems caused by the increase in the movement of commercial vehicles (Fusco et al., 2003; Taniguchi et al., 2003). However, it should be borne in mind that the cooperation of companies with CEPs is economically justified only with the realization of sufficient demand (Park et al., 2016).

The concept to which more and more attention has been paid in recent years is crowdsourcing. It implies outsourcing of logistical tasks to individuals, who perform them with the help of their own resources (means of transport, household storage space, transshipment resources, etc.) (Tadić \& Veljović, 2020a; Carbone et al., 2017). This concept is considered in the context of solving logistical problems in urban areas (Mehmann etal., 2015), but also in rural areas (Tadić \& Veljović, 2020a; 2020b), where this concept can be especially important for supplying the old population. Many large companies hire crowd-workers to make deliveries (Arslan et al., 2018). Expressing and accepting delivery requests can be realized through crowd-logistics mobile applications and social networks (Devari et al., 2017; Dablanc et al., 2017). The delivery fee can be in cash or in the form of a discount provided by the supplier (Hübner et al., 2016). Crowd delivery has a number of advantages. The main advantage is the number and territorial dispersion of potential executors of deliveries and flows that they realize every day. This allows for increased speed and flexibility of delivery, reduced operating costs and the elimination of fleet investment costs. Also, the number of failed deliveries and negative environmental impacts are reduced (Wang et al., 2016). Applying the crowd delivery concept achieves economic benefits for all parties involved (Mehmann et al., 2015). This delivery is most effective in conditions of fluctuating demand on a daily and long-term basis (Joerss et al., 2016). Since one worker usually realizes only one or several deliveries, the communication channel is much more efficient. However, there are a number of disadvantages and challenges in applying this concept. The main challenges relate to reliability and security of delivery. Namely, crowd-workers usually remain anonymous, leading to unreliability and risk of theft of goods. Therefore, it is necessary to introduce stricter verification of the identification of executors and enable the customer to track the shipment in real time (Wang et al. 2016). These problems can also be solved by hiring well-known crowd-workers (relative, friend, associate, neighbor, etc.) (Devari et al., 2017). Also, it is necessary to solve the problems related to legal restrictions in the application of crowd delivery, which exist in many countries.

In addition to complete delivery from supplier to customer, crowd-workers can realize deliveries from CDP to customer. This model requires a smaller number of CDPs and thus lower investment costs (Wang et al., 2016). In addition to crowd-workers, mobile unattended CDPs, i.e. automatically guided vehicles with lockers could be used in the future to deliver goods to the customer's 
home address, Vehicles receive goods at the initial location and transport them to locations close to the customer (Joerss et al., 2016; DHL, 2014).

However, the customer usually realizes the delivery from CDP, as well as from the workplace or neighbor's household to the home address. Customer most often seeks to combine pick-up with other travel (e.g. shopping tours, work-to-home trips, etc.) (Weltevreden \& Rotem-Mindali, 2009) to reduce distance traveled, costs and time lost.

The last part of the delivery can be realized by drop-off companies and local agents. Drop-off companies receive, store and deliver goods to the home address of customers in the local area. After receiving the goods, the company notifies the customer and asks to specify the time window within which the goods can be delivered (Fernie \& McKinnon, 2009). This concept is most commonly applied to delivery in remote and rural areas (Browne et al., 2001). In an identical way, local agents (individuals, i.e. households) participate in home deliveries. They collect and forward customer orders (usually friends and neighbors) to supplier, receive the goods and deliver them to home addresses of customers at a convenient time. This concept has been used in the past by mail order companies, but has been less important in recent decades (McKinnon \& Tallam, 2003).

\subsection{Reception Method and Security of Delivery}

The criterion according to which the classification of home delivery models is most often performed is the method of receiving goods, i.e. the presence of the customer. This classification is one of the most important both in terms of costs and service levels (Vanelslander et al., 2013; Agatz et al. 2008a; Boyer et al., 2005). The basic division of deliveries is into attended and unattended delivery, within which there are different models (McKinnon \& Tallam, 2003) (Fig. 8). Types of attended deliveries differ primarily in terms of time of realization (subsection 2.9.), and unattended deliveries differ in the end point, applied solutions and level of security. Security is one of the most important characteristics of delivery. Security/ safety risks are related to endangering: the integrity and quality of goods, property and members of the household and the environment. Stealing of goods is one of the basic risks. Securing goods from stealing is most often achieved by using multi-sensor devices deeply integrated into the shipment and appropriate tracking software (Ghajargar et al., 2016). Also, goods should be protected from harmful physical, chemical and biological influences in order to preserve their quality. The security of property and household members can most often be endangered by malicious people who work as delivery executors or present themselves as such. Through longterm cooperation, acquaintance and trust between the customer and the supplier, such problems can be eliminated. Safety risks in relation to the environment relate primarily to possible accidents during transport in densely populated residential areas. The delivery options according to reception method and their basic characteristics from the aspect of security are described below. 


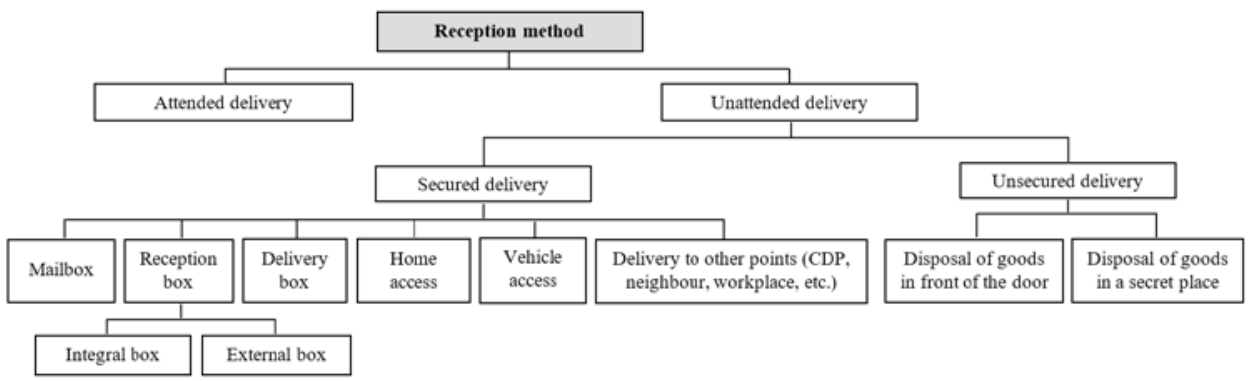

Fig. 8.

Reception Methods in Home Delivery

Source: based on (McKinnon \& Tallam, 2003)

In the case of attended delivery, the customer must be at the end point (usually the home address) during the realization of the delivery, in order to receive the goods and (or) enable the realization of additional services (assembly, installation, personal services, etc.). Depending on the type of goods, this reception method is desirable in some situations, and in some even necessary (subsection 2.11.). Attended delivery has advantages and disadvantages. It allows the supplier to interact directly with the customer (Hübner et al., 2016). Applying this model simplifies payment, which can be made upon delivery. Also, customers can check the correctness of the goods and make complaints, which usually simplify the management of return flows (Tadić \& Veljović, 2020c; Daduna \& Lenz, 2005). However, a significant number of customers do not use delivery services precisely because they require staying at home and waiting (Fernie \& McKinnon, 2009). A large number of attended deliveries are realized unsuccessfully due to the absence of the customer (Gevaers et al., 2009). There are also significant security challenges. Customers often do not know the delivery executors, so the persons who presented themselves as executors committed many criminal acts (Kim et al., 2014).

The problem of the customer's dependence on delivery deadlines can be overcome by applying unattended deliveries. The basic division of unattended deliveries is into unsecured and secured deliveries (McKinnon \& Tallam, 2003), but also within these categories there are models that are characterized by different levels of security. Unattended deliveries can be used as a substitute for attended deliveries or after an unsuccessful attempt to realize them, in order to avoid the realization of return flows (Tadić \& Veljović, 2020c) and possible re-deliveries.

Unsecured unattended delivery involves placing the goods in front of the customer's door or in a secret place known only to the customer and the supplier (Morganti et al., 2014b; Fernie \& McKinnon, 2009; McKinnon \& Tallam, 2003). This delivery model allows for abuse by the customer (e.g. the customer has taken over the goods but informs the supplier that he has not), the supplier (e.g. the supplier has not delivered the goods but informs the customer that 
he has) or other persons (e.g. passers-by, neighbours or persons following the supplier with the intention of stealing the goods, burglars who can conclude on the basis of storing the goods in front of the door that the customer is not at home, etc.) (McKinnon \& Tallam, 2003). Also, temperature and weather conditions can negatively affect goods stored outside the house (Reyes et al., 2017). Nevertheless, companies that offer this delivery model to customers claim that it does not cause serious problems and also significantly reduces the number of failed deliveries (McKinnon \& Tallam, 2003). Criminal activity is likely to increase with more extensive application of this delivery model.

Secured unattended delivery can be realized in various ways. The following concepts will be described below: access to household facilities or means of transport, application of traditional mailboxes, reception and delivery boxes.

The customer can allow delivery person to independently access the household facilities (usually auxiliary; McKinnon \& Tallam, 2003), applying modern technologies and informing the customer about the realization of the delivery. Delivery person can put the goods in the desired place in the facility (e.g. in the refrigerator or freezer) (Langley, 2019). Although this system can increase productivity and reduce delivery time, some companies that have implemented this model have failed (Fernie \& McKinnon, 2009). Also, security and privacy risks need to be addressed (theft of goods by delivery persons, burglary, theft of customer property, etc.) (McKinnon \& Tallam, 2003). These risks could be overcome by applying a system of monitoring delivery person or by applying other reception methods that exclude access to facilities.

The goods can also be delivered to the trunk of the customer's car. Some companies provide this service to customers who own adequate vehicles. Security and communication technologies that allow the delivery person independent access to the trunk are integrated into the latest car models (Reyes et al., 2017). The end point of delivery differs in relation to the location of the vehicle (home address, workplace, etc.).

Reception method, which has been present in practice for a long time, is delivery to the mailbox. In this way, small goods can be delivered to the customer. Also, the goods that are delivered to the mailbox usually have a low value, since there is a possibility of simple burglary and theft.

The reception box has an identical function as a mailbox, but with additional possibilities in terms of access, delivery size and storage conditions. A reception box is a refrigerated, customer specific reception box, installed in the customer's facilities or yard (Punakivi et al., 2001). Access to the reception box can be provided in various ways. Early models had a keyboard that allowed communication with the vendor service center and could be activated by a PIN code issued to the delivery person, but in order to reduce costs most companies stopped using such a system (Fernie \& McKinnon, 2009). The reception box usually consists of three chambers, which maintain a temperature suitable for ambient, refrigerated and frozen goods. The application of the reception box usually implies a stronger connection between the customer and the supplier. Reception boxes, which are often sold and 
installed by the suppliers themselves, are usually used for regular scheduled deliveries of groceries and in that way provide the supplier with customer loyalty. There are two types of reception boxes, integral and external (McKinnon \& Tallam, 2003). Integral reception box is an integral part of a household facility, which can be built in during construction or later upgrades (Fernie \& McKinnon, 2009). It is sometimes set up to allow access to the delivery person on one side and to the customer on the other, directly from the kitchen (McKinnon \& Tallam, 2003). In addition to receiving, the reception box can be used for storage (Wang et al., 2014). In the case when it is connected to the kitchen, it can serve as a replacement for a pantry, refrigerator. The supplier can then monitor the customer's inventory without access to the facility and provide him with a delivery service according to the VMI concept (subsection 2.1) (Smaros \& Holmstrom, 2000; Kämäräinen et al., 2001a; Kämäräinen \& Punakivi, 2002). The integral reception boxes are still insufficiently applied. The main reason is high investment costs (Kämäräinen \& Punakivi, 2002). Some companies have gone bankrupt because they failed to recoup the funds invested in the reception boxes of customers (Agatz et al., 2008b). The main security challenge of this system is facilitated access to burglars (McKinnon \& Tallam, 2003). A more favorable solution from the aspect of costs and security is an external reception box. The installation of the external box does not require structural changes in the household. These boxes are usually made of tough composite materials and/or metals and are tightly attached to the ground or external wall (McKinnon \& Tallam, 2003). They are suitable in situations where the customer wants to disable direct and indirect access to facilities, due to the high value of the property (Wang et al., 2014). Security risks relate exclusively to the contents of the box. The investment of a reception box can only be justified when the customer regularly uses the home delivery service (Fernie \& McKinnon, 2009). Also, the possibility of using a reception box depends on the degree of urbanization of delivery area and the independence of the household (subsection 2.8) (Tadić \& Veljović, 2020a; Boyer et al., 2009). As the use of individual reception boxes is not possible in collective housing facilities, in this case cabinets composed of several reception boxes (communal/shared reception box) are used, located within the common space of the residential building. This solution is identical to the unattended CDP and uses technology similar to luggage lockers applied at railway stations and airports around the world (McKinnon \& Tallam, 2003).

The delivery/thermo box is another solution for unattended delivery. It is an insulated secured box equipped with a docking mechanism (Punakivi et al., 2001). Some authors consider this solution as a mobile reception box (McKinnon, \& Tallam, 2003; Wang et al., 2014). The supplier fills the delivery box on its premises, delivers it to the customer's home address and attaches it to the external wall (McKinnon \& Tallam, 2003). Also, in some cases, the box is connected to an electronic device, similar to an intercom, using a steel cable (Fernie \& McKinnon, 2009). In residential buildings, where such disposal is difficult, the box can be stored in common areas or at the porter of the building (Hays et al., 2005). Delivery boxes are also often used for regular scheduled deliveries, whereby during delivery is taken over the box from the previous delivery and thus at the same time return flows are realized (subsection 
2.10.) (Tadić \& Veljović, 2020c). Punakivi et al. (2001) found that when integrating deliveries and return flows, the operating cost of using a delivery box is at the same level as with a reception box. According to research (Kämäräinen et al., 2001a; Punakivi \& Saranen, 2001; Punakivi et al., 2001), the operating costs of unattended delivery using a reception or delivery box are lower than in the case of attended deliveries with defined time windows. However, the high investment costs of using a reception and delivery box should be borne in mind (Kämäräinen \& Punakivi, 2002). Also, in the case of attended delivery, costs may be increased due to the implementation of additional services (Punakivi \& Saranen, 2001). However, although it offers a number of benefits, the delivery box system has not proven to be commercially viable in the $\mathrm{B} 2 \mathrm{C}$ market after supermarkets in some countries tested its application (Fernie \& McKinnon, 2009).

Unattended deliveries also include deliveries to other end points (neighbor's household, workplace, CDP, etc.) where the customer is not present at the time of delivery (Fernie \& McKinnon, 2009; McKinnon \& Tallam, 2003; Punakivi, 2003). Although deliveries are made without the presence of the customer, other persons may participate in the receiving goods (CDPs staff, neighbor, local agent, employee of the company in which the customer is employed). The advantage of the presence of a person at the receiving goods is to ensure the physical transfer of them and the creation of paper or other evidence of reception and delivery of goods. On the other hand, it is the presence of staff that increases the possibility of theft or fraud. Due to high attendance, attended CDPs are very risky. The risk depends on a number of factors: nature of the premises, working hours, geographical location, the administrative procedure for recording the arrival and departure of goods, storage facilities, staffing policy and the volume of orders handled (McKinnon \& Tallam, 2003). Most stores, gas stations and other places used as CDPs do not have secure storage space for non-food products of higher value (which are most often delivered to CDPs), because they usually sell other types of goods. Security problems could be solved by installing secure warehouses, applying modern technologies and rigorous user authentication procedures. In the case of unattended CDPs, there are no listed staffing risks, but it is also necessary to implement security systems that prevent misuse or theft. Although introduced to improve service levels, complex security procedures can overburden customers and discourage them from using CDPs for delivery (Yuen et al., 2018).

\subsection{Delivery Area}

The delivery area can be considered from two aspects, coverage and degree of urbanization, i.e. demand density (Fig. 9). In terms of area coverage, deliveries are divided into local, regional, national and international/global (Hübner et al., 2016; De Koster, 2003). Coverage of the delivery area is related to a number of factors: market situation, distribution network structure, degree of outsourcing and efficiency of executors, sales channels, type of goods, etc. A supplier who plans to offer a delivery service in some market must have a potentially high demand in order to achieve profitability. He must also provide a developed distribution network, either independently or by hiring a logistics provider. The local deliveries are usually realized by supplier independently, while for deliveries in a wider area (especially global ones) one or more logistics providers are usually hired (De Koster, 2003). 
With the expansion into new markets, numerous challenges and problems arise: new delivery codes in the information system, transformation of the operation of sorting systems, new marking system for shipment, documentation in other languages, ignorance of international import duties and taxes, etc. Small number of companies has a global distribution network and the ability to overcome these challenges, which complicates and geographically limits the organization of global deliveries.

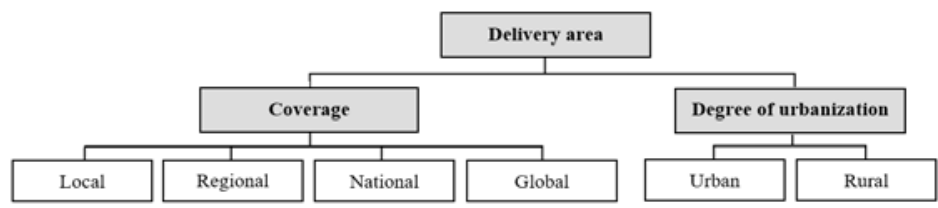

Fig. 9.

Coverage and Degree of Urbanization of Home Delivery Area

One of the key characteristics of home delivery is the demand density, i.e. the number of customers in a certain area (Vanelslander et al., 2013). Demand density is a major factor in pricing different delivery models (Yrjölä, 2001; Boyer et al., 2005; Joerss et al., 2016). The spatial concentration of customers enables the unifying of their requirements in order to achieve efficiency and economic profitability of deliveries. Therefore, suppliers try to attract customers from the same area (Kämäräinen \& Punakivi, 2002). As demand density increases, efficiency increases and last mile delivery costs fall (Boyer et al., 2009), but only to a certain level (Vanelslander et al., 2013). Demand density varies according to the degree of urbanization, population size and density. Higher population density or concentration of households in the urban area provides significantly higher efficiency of routing vehicles in delivery than in the case of very distant households from each other in the rural area (Tadić \& Veljović, 2020a; Boyer et al., 2009). For this reason, deliveries directed to rural areas can be three times more expensive than urban ones (Boyer et al., 2009; Gevaers et al., 2014).
Also, traffic conditions differ significantly, given the much more numerous flows and potential congestion in urban areas. Finally, most home delivery companies are located in cities.

In addition to these, the efficiency, characteristics and quality of delivery in different areas can be affected by numerous other factors: the starting point, the end point, the method of receiving goods, etc. In a mature e-retail market, dedicated LC can be a starting point for deliveries in urban areas, while stored based picking is more efficient for supplying rural areas (Fernie \& McKinnon, 2009). The workplace is the end point most often in urban areas. CDPs can cover urban, suburban and rural areas (Morganti et al., 2014a). Attended CDPs are most commonly found in stores in densely populated urban areas, while, due to the small number of such facilities, unattended CDPs are more commonly located in rural areas (Hübner et al., 2016). The exceptions are post offices, which also are CDPs in rural areas (Browne et al., 2001). The average customer distance from CDPs usually decreases with population density, so it is higher in rural 
areas than in urban areas (Morganti et al., 2014 b). Although they also function in rural areas, deliveries to CDPs are usually more economically successful in areas that offer high demand density (Browne et al., 2001). Household characteristics as end points have a particular impact on deliveries in different areas (Tadić \& Veljović, 2020a). Typical households in the inner city area are usually part of multi-story buildings for collective housing. Such facilities have a common infrastructure (entrance, hallway, elevator, etc.), which can affect the manner and time of delivery. They are not suitable for the use of individual reception and delivery boxes (Daduna \& Lenz, 2005), so in this case, community reception boxes are most often used (Punakivi \& Tanskanen, 2002). On the other hand, households in suburban and rural areas are most often independent buildings with a yard and have direct access to public roads. Such households are, from the aspect of convenience and security of delivery, much more suitable for unattended variants of receiving goods (Tadić \& Veljović, 2020a; Wang et al., 2014; Boyer et al., 2009). The structure of goods and frequency of delivery depend on the functions of the household. Urban and suburban households can have a residential or residential-business function, and rural households can also be used for agricultural production. Agricultural production can provide rural households with some goods for everyday consumption, while urban and suburban households must procure all consumer goods. On the other hand, rural households generate demands for goods needed for the process of agricultural production.

Home deliveries are most often related to cities, as a large proportion of them have a starting or end point in urban areas (Browne et al., 2001). In countries with underdeveloped e-commerce, delivery services are usually provided only in the central zones of large cities. A large number of papers analyze e-commerce and home delivery in the context of urban areas (Dablanc et al., 2017; Visser et al., 2014; Gevaers et al., 2014; Durand \& GonzalezFeliu, 2012). Not only the increase in home delivery number, but also the development of city logistics as a scientific discipline during the last decades contributes to the growing interest in home delivery in the context of urban areas. Relatively short travel distances and the use of smaller vehicles are the main similarities between home delivery and traditional delivery to commercial facilities in the city, but there are also significant differences in terms of shipment size and delivery end points (Visser et al., 2014).

B2C e-commerce and home delivery are increasingly expanding beyond urban areas. In some countries, rural areas generate more deliveries per capita than urban ones, but the total number of deliveries is higher in urban areas due to higher population size (Cárdenas et al., 2017; Clarke et al., 2015). In these countries, the number of vehiclekilometers traveled in deliveries in urban and rural areas is almost identical (Cárdenas et al., 2017), which is a consequence of the large mutual distance of delivery end points (households) in rural areas. On the other hand, the decrease in the number of vehiclekilometers traveled during traditional shopping due to the transition to online shopping is most pronounced in rural areas, as households are further away from stores (Weltevreden \& Rotem-Mindali, 2009). Numerous problems arise with deliveries in rural areas. Poor infrastructure and inaccessibility of the terrain, unfavorable weather conditions can significantly hamper deliveries, especially in mountainous rural 
areas. Also, finding the end point of delivery can be difficult due to incomplete customer address information (Browne et al., 2001). In such circumstances, delivery executors are often local postal services, charities, social and local government organizations, mountain rescue services, but can also be crowd-workers (Tadić \& Veljović, 2020a, $2020 b$ ) or informal groups of individuals and households.

\subsection{Speed and Time of Delivery}

Home delivery can be realized in different ways from the aspect of speed and time of delivery. Delivery speed refers to the time between ordering and receiving goods (delivery lead time), and the delivery time is the moment or period when the delivery should be made. From the aspect of speed, there are multi-day, next-day, the sameday and instant delivery (Winkenbach \& Janjevic, 2018; Hübner et al., 2016; Xu et al., 2008) (Fig. 10). In terms of time, deliveries are divided into defined and undefined (Hübner et al., 2016; Allen et al., 2007) (Fig. 11). The speed and time of delivery depend on a number of factors, but the type of goods and costs are crucial for customers (Joerss et al., 2016). They are considered mainly in the case of attended delivery to home address, because this concept of delivery implies the greatest dependence of the customer on the time of delivery. The conflicting goals of the customer and the supplier are most pronounced in terms of speed and time of delivery. On the one hand, these characteristics have a significant impact on the quality of service. Customers usually want fast, time-defined delivery, because otherwise they have to stay longer at their home address. According to research (see Hausmann et al., 2014), for $28 \%$ of customers speed is the most important characteristic of delivery (has the largest share in addition to the delivery price), and for $11 \%$ it is the flexibility of delivery time. Therefore, time and speed are the main factor in the competition of companies that provide delivery services (Yaman et al., 2012). On the other hand, short deadlines and precise defining of delivery time negatively affect planning, efficiency and delivery costs. Over $50 \%$ of homes are empty between 9 a.m. and 4 p.m., making delivery impossible for most of the delivery executor's working hours (Browne et al., 2001). Most e-commerce customers want goods to be delivered between 6 p.m. and 8 p.m., from Thursday to Sunday (see Xu et al., 2008). This leads to demand peaks on a daily and weekly basis, which make it much more difficult for supplier to organize deliveries. At the same time, the realization of deliveries depends on environmental conditions, traffic (time of peak load, congestion) and legal regulations related to the time of delivery (Tadić \& Zečević, 2016). Also, the speed and time of delivery are affected by the peaks that the supplier has on an annual basis, i.e. seasonal and demand related to certain events (holidays, discount days, etc.) (Lee \& Whang, 2001). Problems caused by demand peaks can be avoided by agreeing and aligning customer and supplier goals in terms of speed and delivery time. The delivery options that the supplier can offer to the customer are described below.

Speed is one of the basic parameters of service quality and, in addition to costs, is a crucial factor for the success of delivery (JDA \& Centiro, 2017; Xing \& Grant, 2006). The speed of delivery depends on the type of goods, the structure of the distribution network, picking point and technology, delivery area, executor of delivery, the level and density of demand, the ordering system, 
etc. The characteristics of some types of goods (time-sensitive, perishable goods, etc.) affect the necessity of fast delivery, while other types of goods do not generate such requirements (Tadić \& Veljović, 2020d) (subsection 2.11). The structure of the distribution network must be adjusted to the fast delivery services (instant, same or next day delivery). The closer picking point is to the customers, the greater the possibility of realization of fast deliveries (Lim et al., 2018). Therefore, the picking of goods that need to be delivered in a short period of time is often done in stores. However, as picking point approaches the customer, the risks associated with stock decentralization arise (Netessine \& Rudi, 2006). Delivery speed can also be increased by applying automated picking in LCs. The delivery area also has a significant impact on delivery speed. Local deliveries can be realized instant, same or the next day, but global deliveries require a much longer delivery lead time, which can be up to several months. The speed of delivery also depends on the delivery executor.
The time between ordering and receiving goods is the longest with postal operators, slightly shorter with package operators and supplier who independently deliver, and the highest efficiency is achieved by local courier services and crowd-workers (Winkenbach \& Janjevic, 2018; Hausmann et al., 2014; Visser et al., 2014). Longer delivery lead times are most often caused by the consolidation of goods, i.e. waiting for the completion of the route (Agatz et al., 2008b). Delivery speed also depends on the time of ordering. Thus, some companies deliver on the same day goods ordered before 8 a.m., and goods ordered after those are delivered the next day (Hays et al., 2005). Delivery speed may also depend on legal restrictions. In some countries, delivery must be made within the statutory timeframe, unless the customer approves a later delivery (Browne et al., 2001). Finally, the speed of delivery depends on the level and density of demand, because fast deliveries are usually not profitable if the number of customer requests in some area is insufficient.

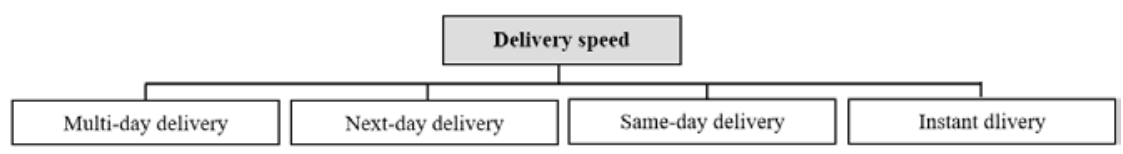

Fig. 10.

Classification of Home Delivery Models from the Aspect of Speed

Hausmann et al. (2014) point out the evolutionary development of home delivery from the aspect of speed. The oldest model involves delivery a few days after ordering (multi-day delivery) and was originally used by mail order companies. Today, this model is also applied by e-commerce companies, especially for non-food products. Many companies receive orders one week and deliver goods to customers the next (Campbell \& Savelsbergh, 2006).
Although fast delivery services have been developing more and more in recent years, in many situations speed is not a priority for customers. Research shows that free or discounted delivery, free returns, monitoring and security of delivery, and the ability to define delivery windows are often more important than speed of delivery (IMRG, 2019; JDA \& Centiro, 2017; Dablanc et al., 2017; Joerss et al., 2016). Such customer preferences also benefit suppliers, as 
increasing the time between ordering and delivery can significantly contribute to improving delivery efficiency by increasing delivery density, reducing the total number of tours required, and distance traveled (Browne et al., 2001).

However, due to different trends (increase in GDP per capita, rapid adoption of e-commerce, urbanization, etc.), customer expectations are directed towards ever faster deliveries (Hausmann et al., 2014). A large number of customers do not practice online shopping precisely because of the long delivery lead time (Joerss et al., 2016). That is why the companies started offering the possibility of next-day delivery. This concept requires a developed distribution network, composed of LCs and numerous local points (branches, agencies, stores, etc.) (Visser et al., 2014). Next-day or two-day deliveries are currently the industry standard in all developed countries (Hausmann et al., 2014), and their number is increasing from year to year (Morganti et al., 2014b; IMRG, 2019).

The next evolutionary step for companies is same-day delivery. Goods are delivered a few hours after ordering or within the time window during the same day. This concept is suitable for customers with urgent needs and lack of time, because it combines the advantages of almost instantaneous goods availability, which characterizes traditional shopping, and remote ordering. It can also encourage sales of both the existing range of goods and categories of products that are not normally sold online (e.g. food products) (Hausmann et al., 2014). That is why more and more companies are introducing or planning to include this concept in their business. However, there are a number of challenges in implementation.
Four prerequisites for enabling same-day delivery need to be met (Hausmann et al., 2014): (local) goods availability, real-time inventory visibility/monitoring, fulfillment capacity and flexible last-mile capability. This requires further transformation of the distribution structure, technologies and operations, and significant investment in IT and logistics infrastructure. At the same time, it is necessary to reduce costs to the level that customers are willing to pay. Hausmann et al. (2014) state that customers consider same-day delivery attractive if they pay $7-8 \%$ of the price of the goods. Significant factors influencing the success of same-day delivery implementation are the level and density of demand. Some companies that established same-day delivery failed due to low demand (Hausmann et al., 2014). Therefore, only densely populated urban areas with high demand and willingness of customer to pay additional costs are eligible for the establishing same day delivery.

Instant deliveries have the shortest time between ordering and delivery of goods. They are realized within two hours (Dablanc et al., 2017). Such delivery is often used by restaurants and grocery stores, in order to ensure the quality and freshness of the goods. Due to the great variability of demand in terms of time and location, couriers and crowd-workers are considered the most suitable executors of instant deliveries (Joerss et al., 2016). They are economically viable only over short distances $(5-10 \mathrm{~km})$, which is why they are most often realized in the inner city area (Joerss et al., 2016). Apart from the area aspect, instant deliveries are also limited in terms of delivery time. In many countries, night deliveries are not allowed, so the current needs of customer for goods cannot be met at that time. 
As mentioned, in terms of delivery time they can be defined or undefined (Hübner et al., 2016; Allen et al., 2007). Defining the delivery time implies specifying the moment or time window in which the delivery will take place, which is determined by the agreement of the supplier and the customer (Daduna \& Lenz, 2005) or the independent decision of the supplier. In the case of undefined deliveries, the customer does not know in advance the delivery time (sometimes not even the exact date). The moment or period in which the delivery will take place directly affects the level of service, as it determines how long the customer must stay at home waiting for delivery (Punakivi \& Saranen, 2001; Kämäräinen \& Punakivi; 2002). On the other hand, delivery time decisions can significantly affect the profitability of delivery service companies (Campbell \& Savelsbergh. 2006). Delivery time is usually defined when ordering goods, but in some cases immediately before delivery. Delivery time, possibility and moment of its defining depend on various factors. One of the factors is the coverage of delivery area. For example, during international delivery, the date and time of delivery are not known reliably at the time of ordering, because they depend on various factors: number, type and efficiency of executors, picking point, degree of consolidation of goods, etc. The level and density of demand in some area also significantly affect the delivery time. Customers from urban areas that generate higher demand can usually choose the day, and in certain conditions the delivery time, and in areas with lower demand the choice is usually not possible, but delivery requests are collected over time, so that after a certain accumulated demand level, customers are notified on the date and time when the delivery will take place (Boyer et al., 2009; Browne et al., 2001). The different level of service in terms of time also depends on the delivery executor and order picking point (Vanelslander et al., 2013). When the supplier realizes delivery with its own fleet from its own LC, it is often precisely defined in time (time slotted delivery). On the other hand, the logistics provider is less likely to use such a delivery organization, because it is not easily feasible when consolidating a large quantity of goods ordered from different customers.

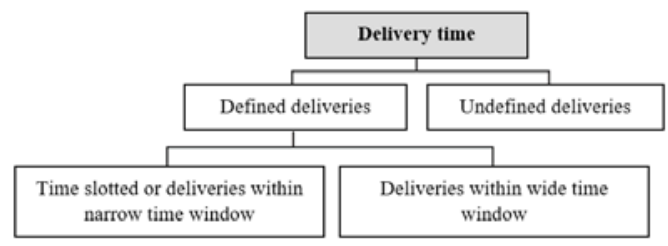

Fig. 11.

Classification of Home Delivery Models from the Aspect of Time

Supplier/delivery executor can, in agreement with the customer, define the moment or the narrow time window in which the delivery will take place. This service is provided by many companies, especially retailers of consumer goods (Agatz et al., 2011). The offer of narrow delivery windows that provides a high level of service is very attractive to customers (Boyer et al., 2005) and contributes to their satisfaction (Hübner et al., 2016). Also, delivery failures can be avoided in this way (Campbell \& Savelsbergh, 2006). On the other hand, there are a number of challenges and problems. Greater freedom 
of the customer in defining the delivery time can significantly reduce the possibility for spatial and temporal consolidation of customer requests in order to increase the efficiency of delivery. Namely, if each customer chooses the appropriate delivery time window, the distances and costs increased and delivery executor's working hours are extended (Punakivi \& Saranen, 2001; Wang et al., 2014), and the possibility of congestion and negative effects on the environment increase. Also, the high demand for certain time intervals and the variable travel time of vehicles can make it difficult to organize the delivery of goods within a narrow time window (Agatz et al., 2011). The complexity of organizing such deliveries requires the application of information and communication technologies and routing software, which also further increases costs. In addition, the increase in distance traveled, costs and negative effects on the environment may be contributed by the absence of the customer, i.e. non-compliance with the agreed delivery time ("ping-pong" effect) (Punakivi et al., 2001; Geavers et al., 2009; Edwards et al., 2009; Slabinac, 2015; Devari et al., 2017). These difficulties and additional costs also affect the increase in the price of the service, which reduces the popularity of this service among customers.

Therefore, companies strive to balance marketing and operational aspects (Agatz et al., 2011), expand time windows and more evenly schedule deliveries within them. Expanding time windows can significantly reduce costs (Hübner et al., 2016; Boyer et al., 2009; Punakivi \& Tanskanen, 2002), as this allows for more efficient routing of vehicles in delivery (Punakivi et al., 2001). Companies offer customers various discounts or incentives for choosing wider delivery windows, as well as choosing windows and slots outside of peak demand, etc. Research shows that customers are more influenced by incentives for wider delivery windows than for time slots (Campbell \& Savelsbergh, 2006).

The highest efficiency of vehicle routing and the lowest costs are due to undefined delivery. The time window of such deliveries is equal to the working hours of the supplier/delivery executor (Gevaers et al., 2009; Punakivi \& Saranen, 2001). Most companies provide customers only with information about date of delivery, which takes place between 9 a.m. and 5 p.m. or 7 p.m. (Visser et al., 2014). This model significantly facilitates delivery planning, but negatively affects customer satisfaction (Gevaers et al., 2009) and increases the likelihood of their absence during delivery ("not-at-home syndrome") (Slabinac, 2015). Some categories of customers (e.g. retirees, unemployed persons) do not have to require a precise delivery date and are ready to receive the goods at any time of the day. Other customers can overcome this problem by using a reception box or other means of receiving goods at the home address without the presence of the customer. In that case, delivery can be realized at any time, in accordance with the optimization of vehicle routing, without the risk of delivery failure. By combining time undefined delivery and a reception box, significant savings are achieved (Hübner et al., 2016; Kämäräinen et al., 2001a).

\subsection{Return Flows}

Home delivery can generate return flows of goods, packaging and logistics units (Tadić \& Veljović, 2020c). Like delivery, return flows that take place at the end of the supply chain require complex organization and generate high costs (Vanelslander et al., 2013). Also, 
the realization of return flows contributes to the increase in the volume of transport and harmful emissions (Edwards et al., 2009). On the other hand, return policy affects the level of service, customer satisfaction and loyalty, choosing the right supplier and selling goods and is considered an important factor of market competitiveness (Tadić \& Veljović, 2020c). Having in mind their importance, in the following, the characteristics of the return flows of goods, and then of the return flows of packaging and logistics units used in home delivery, will be analyzed in more detail. Also, the structuring and classification of return flows realization models according to different criteria will be performed.

In the context of return flows, returnability is the network's ability to process returned goods (Chopra, 2003). Characteristics, complexity of the organization of return flows of goods and the return rate depend on many factors (Tadić \& Veljović, 2020c): ordering system, starting and end point of delivery, reception method, security, time and speed of delivery, additional services, types of goods, return prices, etc. (Fig. 12).

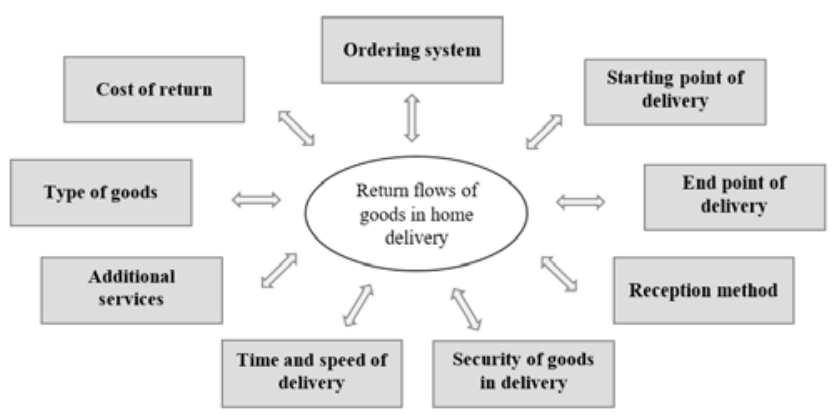

Fig. 12.

Factors Influencing the Realization of Return Flows in Home Delivery

The ordering system has a significant impact on return flows. Deliveries of goods ordered remotely generate a large number of returns because customers do not have direct and complete insight into the characteristics of goods at the time of ordering (Tadić et al., 2015), so goods, that by type, quality or quantity does not correspond to the order, can be delivered to them, which causes their dissatisfaction (Tadić \& Veljović, 2020c). In order to reduce the number of returns, the concept of $\mathrm{O} 2 \mathrm{O}$ (subsection 2.2) or personal ordering in the stores is applied (Bernon et al., 2016).
The realization of return flows largely depends on the distribution network for the realization of deliveries, so the end point of the return flow often coincides with the starting point of delivery (Tadić \& Veljović, 2020c). As the distance of the customer from the end point of the return flow increases, the complexity and costs of realization increase, due to which the number of returns decreases (Lim et al., 2018). The goods are rarely returned directly to the manufacturer, because he is usually the furthest from the customer, and the rate of return is highest at retailers with a dense network of stores or CDPs that accept returned goods. 
The end point of delivery and the reception method affect the rate of return, time and manner of realization of return flows (Tadić \& Veljović, 2020c). When delivered to the home address in the presence of the customer, the customer can check the characteristics and correctness of the goods and make possible complaints to delivery executor, which usually simplifies the realization of return flows simplifies (Hübner et al., 2016), which is not the case with deliveries to other points (neighbor's household, workplace, CDP, etc.) and other unattended deliveries.

Security of goods in delivery, time and speed of delivery and additional services are also factors that affect the realization of return flows (Tadić \& Veljović, 2020c). The security of the goods in delivery is crucial for preserving their quality, correctness and integrity and reducing returns due to damage, so it is necessary to ensure adequate handling, packaging and transport of goods. Delivery time and speed have an impact on the rate of return, as delivery delays increase the likelihood of returns (Xing \& Grant, 2006). Additional services provided by some suppliers may also affect the rate of return
(Agatz et al., 2008b). Thus, the services of assembling and locating furniture in the customer's facility and installing electronic products can reduce the number of returns.

The type of goods is one of the key factors influencing the characteristics of return flows (Tadić \& Veljović, 2020c; 2020d). The dependence of return flows on the type of goods will be described in subsection 2.11.

Finally, the characteristics and number of return flows depend on the price (Tadić \& Veljović, 2020c). When returns are free, customers often order more goods (usually clothing) than they need because they want to try it, which increases the number of returns and the complexity of their organization. For these reasons, suppliers are increasingly charging for returns.

Return flows in home delivery can be structured according to different criteria: cause and time of realization, executor, integration with deliveries, end point, etc. (Fig. 13) (Tadić \& Veljović, 2020c). The classifications of return flows realization models according to these criteria will be described below.

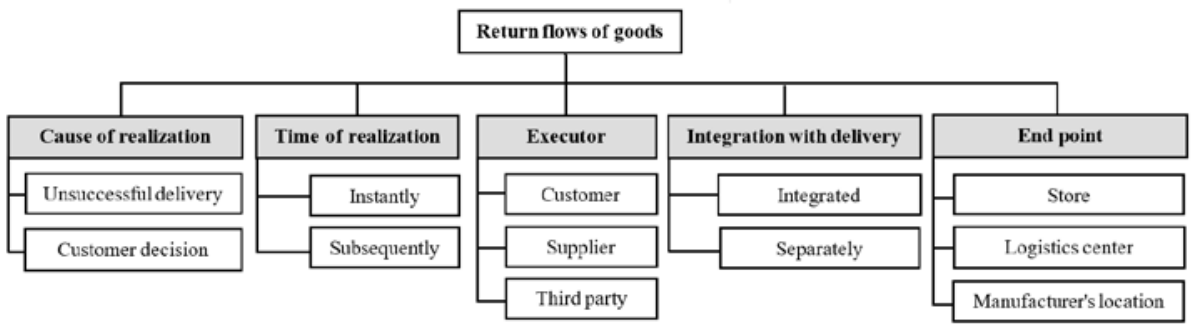

Fig. 13.

Structuring and Classification of Return Flows Realization Models in Home Delivery Source: (Tadić \& Veljović, 2020c) 
The causes of the realization of return flows can be different. They are realized due to the unsuccessful delivery or the customer decision to return the goods (Tadić \& Veljović, 2020c). The most common causes of unsuccessful delivery are the absence of the customer ("not at home" syndrome) and the inability to realize unattended reception (Tadić et al., 2015). Also, the customer can return the received goods due to unfulfilled expectations, damage, change of decision (the customer bought the goods due to promotion but in the meantime made a decision not to accept it) and rejection of inappropriate alternatives (customer orders several alternatives with the intention to return inappropriate).

Return flows also differ from the aspect of realization time. There are instant and subsequent returns (Tadić \& Veljović, 2020c). In the first case, the customer is absent or refuses to receive the goods, so the delivery executor realizes the return with the same vehicle immediately after delivery. In the second case, the customer receives the goods and subsequently makes a decision to return the goods. The time, but also the complexity of the organization and rate of return depend on the type of goods, the end point of delivery and the reception method.

Return flows can be realized by customers, suppliers or a third party (logistics provider, crowd-worker) (Tadić \& Veljović, 2020c). The customer usually realizes subsequent returns of goods to the stores. The key factors for the successful realization of return flows for customers are the ease of return and the number of points at which they can be realized (Bernon et al., 2016). Therefore, the realization of return flows by the customer is particularly suitable for "click \& mortar" retailers, who have developed network of stores near customers (Edwards et al., 2009). Also, customers can return the goods to the CDP, from where the suppliers ship them to the end point of the return flow. Some suppliers include a complete return flow organization in the delivery service, which is free or paid for by the customer (Browne et al., 2001). Suppliers realize instant and subsequent returns, trying to integrate them with deliveries. This concept is very attractive to customers, but requires higher costs than returning goods to stores by customers (Chopra, 2003). The customer or supplier can also hire a logistics provider (CEPs, postal operators, etc.) (Hübner et al., 2016) or crowd-worker (Pan et al., 2015) to realize the return flows. According to research, when choosing a logistics provider, half of the customers opt for CEP and half for postal operators (Edwards et al., 2009). Crowd-workers can also be hired for the realization of return flows, which can significantly affect the reduction of negative economic, environmental and social impacts caused by the traditional way of realization of returns (Pan et al., 2015). Also, suppliers often use a hybrid strategy to offer customers a wider choice. Thus, some companies allow customers to independently return goods in stores, but also through CEPs and postal operators (Bernon et al., 2016).

The realization of return flows largely depends on the integration with delivery (Tadić \& Veljović, 2020c). Return flows can be integrated with deliveries or realized separately. Suppliers strive to integrate return flows with deliveries, to reduce distance traveled and the number of empty runs. CEPs are also increasingly integrating deliveries and return flows (Edwards et al., 2009). Return of goods is associated with their delivery (instant return) or other deliveries (subsequent return). 
For the realization of return flows, the distribution network for the realization of deliveries is most often used, which is why it must be additionally adjusted (Tadić \& Veljović, 2020c). The end point of the return flow is the point where the returned goods are processed and most often coincides with the starting point of delivery (locations of retailer or manufacturer) (Tadić \& Veljović, 2020c). Return of goods to the end point can be realized directly or through CDPs. Suppliers use attended of unattended CDPs to speed up the handling of returns and improve the efficiency of the realization of return flows to the end point. Retailers can use stores or LCs to process the returned goods. Stores are most commonly used by "click \& mortar" retailers, reducing infrastructure investment and return flow management costs (Agatz et al., 2008b). Also, returned goods can be sold in stores after processing. This concept is very suitable for customers, but also for retailers, given the ease of realization of return flows. On the other hand, there may be problems in accepting and processing returned goods, as stores are not designed and equipped for these operations (Chopra, 2003), as well as in managing large quantities of returned goods that the retailer cannot resell (Bernon et al., 2016). These disadvantages but also the advantages of this concept are not present in the application of LCs for the realization of returns. The return end point can be the retailer's LC from which the goods are delivered or a dedicated return LC (Morganti et al., 2014b).

Analogous to the concept of drop shipping applied in delivery, the end point of return flows can be the location of the manufacturer or retailer's supplier (Tadić \& Veljović, 2020c). This concept is not efficient in most cases, requires high costs and complex flow coordination (Chopra, 2003), which is why it is rarely applied (Lim et al., 2018).

In addition to goods, return flows in home deliveries can consist of packaging and logistics units (Tadić \& Veljović, 2020c). Glass, aluminum and stainless steel packaging is usually used as reusable packaging for deliveries. Different logistics units can be used for home delivery, but since the quantity and volume of goods in delivery are usually small (Visser et al., 2014), pallets are used on rare occasions, while miniload units (especially delivery boxes) are used much more often. Return flows are most often integrated with regular scheduled deliveries of groceries. The supplier fills the packaging and packs it in a delivery box. Upon delivery, it takes over the box from the previous delivery and realizes its return. In this way, milk delivery and packaging return flows have been realized in the past (Gould, 1998), and in recent years supermarkets have increasingly used delivery boxes for grocery delivery.

\subsection{Type of Goods}

The type of goods is one of the key factors on which other delivery characteristics depend (Tadić \& Veljović, 2020d). There are different classifications of goods. According to the most common market classification, goods are divided into (Daduna \& Lenz, 2005): convenience/consumer goods (food, drugstore goods, etc.), shopping goods (clothing, footwear, etc.) and specialized goods (furniture, white goods, etc.). These product categories differ in the frequency of purchase, which is the highest for the first and the lowest for the last group of goods. Socio-demographic characteristics of the household and the tendency to use home delivery services determine 
whether the frequency of deliveries will be fully harmonized with the dynamics of consumption. At the same time, customer needs and preferences affect delivery characteristics in terms of need for ordering. Thus, deliveries of consumer goods can be realized regularly scheduled/with partial ordering, and other product categories are most often delivered on demand. A similar classification is introduced by Gevaers et al. (2009) in relation to shelf life, value and basic characteristics of goods, distinguishing between non-durable/fast moving consumer goods/groceries and durable goods (Fig. 14). Groceries are usually of lower value, and durable goods can be of medium (e.g. books, CDs) or high value (e.g. computer and electronic equipment). Also, durable goods can be divided into goods of small and large dimensions (Browne et al., 2001; Allen et al., 2007), which affects the characteristics of logistics requirements.

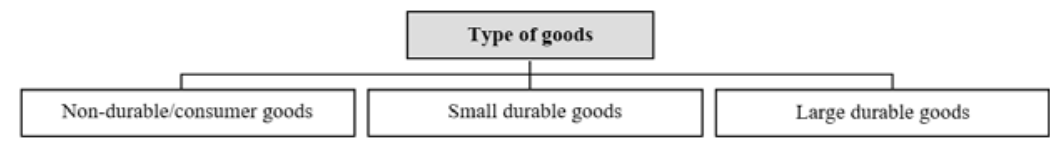

Fig. 14.

Classification of Goods for Home Delivery

There are other classifications of goods from the aspect of logistical requirements. Daduna and Lenz (2005) distinguish between package goods, hanging goods and general cargo. In general, there are goods that generate and those that do not generate specific logistical requirements (De Koster, 2002a). Specific requirements contribute to the complexity of logistics processes and operations and may relate to warehousing, handling, order picking, packaging, transport, reception of goods, security, speed and timeliness of delivery, etc. They depend on the physical and chemical characteristics of the goods, the characteristics of demand and consumption (time-sensitive goods, e.g. daily newspapers, New Year's decorations), the value of the goods, the requirements for the protection of customer privacy, etc. Handling and transport are realized in accordance with the rules and labels that refer to goods sensitive from different aspects (position of goods, fragility, flammability, etc.). Goods with specific physical characteristics (goods of large dimensions, easily breakable, sensitive to shocks, etc.) generate special requirements from the aspect of handling, packaging and transport in order to preserve integrity and quality. Protection of easily breakable and sensitive products from the aspect of packaging is usually provided by the use of styrofoam, air foil and other materials that prevent damage. Adverse chemical and biological effects are also prevented by adequate packaging and transport conditions.

The most complex requirements are generated by the delivery of food products. The requirements relate to the preservation of product quality and freshness, temperature, compatibility of goods, speed of delivery, realization of return flows, etc. Also, these deliveries are subject to strict regulations and quality standards (De Koster \& Neuteboom, 2001; De Koster, 2002a). The complexity of the organization and realization of delivery leads to high costs, and the margins of food products 
are significantly lower (De Koster, 2002b; Campbell \& Savelsbergh, 2005). As a result, milk delivery, which was widely practiced in the last century, almost disappeared when supermarkets began to compete with their prices (Gould, 1998). Food delivery models can be classified in terms of the degree of food processing and temperature conditions. Companies provide customers with three options (Dablanc et al., 2017): grocery delivery, delivery of ingredients with a recipe for the preparation of a dish, and delivery of prepared food. Customers order groceries for food preparation, wanting to have an insight into their quality and to prepare food independently. The extension of this service is the delivery of ingredients of certain dishes with recipes. This concept can bring benefits to both the customer (variety and new dishes) and the supplier (sale of a diverse range of goods) (Cairns, 1996). The lack of free time and the consumerist way of life have encouraged the ordering of prepared meals in recent decades (fast food deliveries are the most common). These delivery models differ in terms of frequency and need for ordering. Grocery delivery is often realized regularly on schedule, and prepared food is usually delivered on demand. From the aspect of temperature, food products are divided into ambient, hot, refrigerated and frozen. Ambient products do not require special conditions (De Koster, 2002b), but are more sensitive than non-food products. These are usually packaged, canned products. Unlike these goods, prepared food is often delivered to consumers hot. This is achieved by adequate packaging and application of instant delivery. In the delivery of refrigerated and frozen goods, it is necessary to provide a cold supply chain (Bogataj et al., 2005). This can be achieved (De Koster, 2002b): by using an insulated delivery box, by using adequate means of transport (with temperature chambers), by transport planning (in order to efficiency and shorten delivery lead time) or by applying logistics outsourcing (by hiring a logistics provider with adequate resources). In addition to temperature, it is especially important to take into account the compatibility of goods in the delivery of food products. For example, goods that emit moisture, heat or a strong odor must be separated from goods that absorb them, etc. Food products should be packaged separately from non-food ones, in order to avoid mutual contamination (Boyer \& McKinney, 2018). It is especially important to separate food from chemical products, so that its quality would not be endangered by harmful toxic effects. Incompatibility of goods can also be expressed in terms of speed of delivery, which may prevent or impede consolidation (Browne et al., 2001). Thus, transport of perishable food, which needs to be delivered in a short time, and durable goods, which do not generate high speed requirements, by the same vehicle and in the same conditions, can significantly reduce the efficiency of planning and implementation of the transport process.

There is also interdependence between the type of goods and the ordering system (Tadić \& Veljović, 2020d). Janz (2001) and Browne et al. (2001) differentiate goods according to suitability for remote ordering. Standardized goods, low and medium value, without specific differences between units of the same product, are suitable for remote ordering (e.g. packaged, long-lasting consumer goods). Nowadays, most goods for delivery are ordered through e-commerce. Also, mail/ catalog sales still apply to some types of goods (cosmetics, toiletries, gifts, cleaning products and equipment, kitchen equipment, etc.) (Browne et al., 2001). On the other hand, 
some types of goods are less often remote ordered by customers, because the units of the same product may differ in quality (fruits, vegetables, flowers, etc.). Also, customers still prefer to personally order some types of goods in stores (furniture, appliances, etc.) or testing goods on the principle of $\mathrm{O} 2 \mathrm{O}$ (clothing, footwear, etc.) (subsection 2.2), in order to gain complete insight into product characteristics.

The type of goods also affects the starting/ order picking point. Consumer goods are sold in supermarkets, where they can be picked before delivery. Deliveries of durable goods can also be made from the point of sale, where the customer personally ordered the goods, but are more often made from the retailer's LC or directly from the manufacturer (Browne et al., 2001; Agatz et al., 2008b; Fernie \& McKinnon, 2009), especially in the case of high value goods (e.g. furniture, white goods, etc.) or goods of short life cycles, in order to reduce inventory carrying costs and risks involved in stock keeping (De Koster, 2002a). Dropshipping is a particularly suitable option for the delivery of seasonal goods that are sold in a relatively short period of the year ( $\mathrm{Ma}$ et al., 2017).

The type of goods also affects the end point of delivery and the way the goods are received. Customers predominantly prefer delivery to home address for both consumer/daily and other goods (Weltevreden \& Rotem-Mindali, 2009). Attended delivery to the home address is necessary for deliveries that require the customer's signature (Weltevreden, 2008), deliveries of high value goods (Campbell \& Savelsbergh, 2006) or goods that are not suitable for unattended delivery (e.g. large goods that cannot be disposal in a mailbox or reception box and are not suitable for storage in CDPs or in a neighbor's household, as well as for independent delivery from these points to the customer's home address). Attended reception is also desirable for deliveries of goods to be exchanged (e.g. DVDs) and deliveries that include additional services (assembly, installation, personal services, etc.) (Punakivi \& Saranen, 2001; Campbell \& Savelsbergh, 2006), but in these situations some of the unattended delivery variants can be applied (e.g. access to the home). In some countries, the supplier has a legal obligation to pick up and take away furniture and appliances to be replaced with new, delivered goods (Browne et al., 2001). The application of unattended delivery model also depends on the type, value and characteristics of the goods. Durable, low-value goods can be disposal in front of the door or in the mailbox, if they are small (magazines, CDs, etc.). For perishable consumer goods, having in mind the characteristics and purpose, delivery models that delay the taking over or consumption of goods (delivery to CDP, neighbors, car trunk, disposal in front of the door, etc.) are not suitable. Since they provide adequate conditions, a reception and delivery box can be used for perishable goods delivery.

The choice of delivery executor also depends on the type of goods. Suppliers deliver consumer goods by their own fleet or by hiring a logistics provider (Durand \& Gonzales-Feliu, 2012). Given the specific properties and logistical requirements of the goods, many suppliers see in-house delivery as a strategic advantage (Hays et al., 2005). For delivery of consumer goods can also be hired logistics providers. However, traditional providers are usually not trained and equipped to deliver refrigerated and frozen goods (De Koster, 2002a; Punakivi \& Saranen, 2001). Therefore, suppliers 
must provide delivery boxes with passive cooling or dry ice (Vanelslander et al., 2013; Hausmann et al., 2014). Delivery of small, low-value goods can be realized by the supplier, but postal and CEP services are more often engaged (Browne et al., 2001). On the other hand, companies selling large (white goods, furniture, etc.) and (or) highvalue goods traditionally have their own distribution channel for home delivery, but logistics providers are sometimes hired to deliver such goods (Browne et al., 2001). Engaging crowd-workers is limited by the value of the goods. In this case, the risk of theft of high value goods by delivery person is very high, so this concept should be applied to lower value goods or by hiring a known and reliable worker (relative, friend, neighbor, etc.) (Devari et al., 2017).

The characteristics and logistical requirements of different product categories allow for different coverage of the delivery area (De Koster, 2003). Goods that do not generate specific logistical requirements can be delivered at all levels of coverage (Tadić \& Veljović, 2020d). On the other hand, the non-resistance of some goods to various physical, chemical and biological influences makes it impossible or difficult to deliver in a wider area of coverage or increases its costs. Therefore, for example, perishable food products are only delivered locally (Fernie \& McKinnon, 2009)

The speed and time of delivery also depend on the type of goods (Browne et al., 2001; Gevaers et al., 2009). The speed of delivery to customers is important for consumer goods and medicines, while they are most willing to wait for the delivery of clothes, accessories and cosmetics (Joerss et al., 2016). Therefore, consumer goods are most often delivered on the day of ordering within predefined time windows, which is usually not the case with other types of goods (McLeod et al., 2006; Browne et al., 2001). Speed is a particularly important factor in the delivery of prepared food, so in this case, instant deliveries are most often used. Deliveries of durable goods are much less frequently defined in time than in the case of consumer goods. The date, and sometimes the time window of delivery, is contracted in advance only for large durable goods (Browne et al., 2001), because failure to deliver such goods brings numerous problems.

The type of goods is one of the key factors influencing the rate of return and the characteristics of return flows (Tadić \& Veljović, 2020c). Due to their characteristics, some types of goods are very rarely returned to the supplier (perishable, time-sensitive, goods produced according to the customer's wishes, etc.) (Browne et al., 2001). According to research, the rate of return of groceries delivered to a home address is less than $1 \%$ (Hübner et al., 2016). However, managing the return of groceries that generate specific logistical requirements, as well as packaging and delivery boxes is very complex. The rate of return is significantly higher for durable, non-food goods (usually 25-30\%; Edwards et al., 2009), but it depends on the type, dimensions and value of the goods. Furniture, white goods and other goods of large dimensions and (or) value have the lowest rate of return, because they are most often ordered in person in stores (Visser et al., 2014), where the customer has a complete insight into the characteristics of the goods. Also, the specific logistical requirements that generate the physical characteristics of goods affect the complexity of the realization of flows and increase costs, which can deter customers from returning. Goods of smaller dimensions and value (books, clothes, shoes, 
etc.) are returned to the supplier much more often (Browne et al., 2001). The rate of return is highest when delivering clothes. On average, it is twice the rate of return in traditional retail (Bernon et al., 2016), and can reach as much as $45 \%$ (Agatz et al., 2008b).

\section{Conclusion}

In recent decades, due to the development of the Internet and e-commerce, an increasing number of companies offer home delivery service. At the same time, different concepts and delivery models are being developed with different characteristics that depend on a number of environmental and stakeholder factors, and which are interdependent.

This paper defines a framework for comprehensive structuring and classifies the home delivery models. In addition, the scientific and practical knowledge about the characteristics, advantages, disadvantages and applicability of the home delivery model in different circumstances is clearly systematized and analyzed in detail. This achieved the basic contribution and goal of the paper, but also created the basis for future research in this area.

The subject of future research may be the impact of last mile delivery on previous phases and flows in the supply chain, distribution network structure and distribution strategy in relation to different circumstances (logistics outsourcing, different coverage of the delivery area, etc.). The possibilities of application of different modes and means of transport in home delivery are a significant and wide area for future research and classification of delivery models. Consolidation of flows and cooperation of participants in the organization of deliveries, as some of the solutions to the challenges in improving efficiency, should also be in the focus of researchers' attention. Delivery models that imply more direct cooperation between the customer and the supplier, i.e. the delivery executor (e.g. access to the home during delivery or checking stocks, insight into the needs and habits of the customer through the application of VMI concept, monitoring the customer's movement through the application of delivery in the trunk, etc.), have a number of benefits for all stakeholders, but also security and privacy risks. These and similar security risks that occur in home delivery should be the subject of research. Humanitarian home deliveries, which are realized by charitable, social, rescue, local government services, and commercial deliveries, that are realized in emergency situations (epidemics, adverse weather conditions, etc.) should also be the subject of future research, given their growing frequency and the importance of the delivery service for supplying households in such conditions. For the same reasons, the subject of research may be deliveries in rural areas, which have been analyzed in a very small number of papers.

\section{References}

Agatz, N.; Campbell, A.; Fleischmann, M.; Savelsbergh, M. 2008a. Challenges and Opportunities in Attended Home Delivery. In: Golden, B.; Raghavan, S.; Wasil, E. (Eds.), The Vehicle Routing Problem: Latest Advances and New Challenges. Operations Research/Computer Science Interfaces, vol. 43. Springer, Boston, 379-396.

Agatz, N.; Campbell, A.; Fleischmann, M.; Savelsbergh, M. 2011. Time Slot Management in Attended Home Delivery, Transportation Science 45(3): 435-449. 
Agatz, N.; Fleischmann, M.; Van Nunen, J. A. E. E. 2008b. E-fulfillment and multi-channel distribution - A review, European Journal of Operational Research 187(2): 339-356.

Allen, J.; Thorne, G.; Browne, M. 2007. Good practice guide of urban freight transport, BESTUFS, Available from internet: <http://www.bestufs.net/download/ BESTUFS_II/good_practice/English_BESTUFS Guide.pdf $>$.

Arslan, A.M.; Agatz, N.; Kroon, L.; Zuidwijk, R. 2018. Crowdsourced Delivery - A Dynamic Pickup and Delivery Problem with Ad Hoc Drivers, Transportation Science 53(1): 1-14.

Bailey, J.P.; Rabinovich, E. 2005. Internet book retailing and supply chain management: An analytical study of inventory location speculation and postponement, Transportation Research Part E: Logistics and Transportation Review 41(3): 159-177.

Bernon, M.; Cullen, J.; Gorst, J. 2016. Online retail returns management, International Journal of Physical Distribution \& Logistics Management 46(6/7): 584-605.

Bogataj, M.; Bogataj, L.; Vodopivec, R. 2005. Stability of perishable goods in cold logistic chains, International Journal of Production Economics 93-94: 345-356.

Boyer, K. K.; Prud'homme, A. M.; Chung, W. 2009. The Last Mile Challenge: Evaluating the Effects of Customer Density and Delivery Window Patterns, Journal of Business Logistics 30(1): 185-201.

Boyer, K.K.; Frohlich, M.T.; Hult, T.G. 2005. Extending the Supply Chain: How Cutting Edge Companies Bridge the Critical Last Mile into Customers' Homes, American Management Association, USA. 252 p.

Boyer, R.; McKinney, J. 2018. Food Storage Guidelines for Consumers, Publication 348-960. Virginia Cooperative Extension, Virginia Tech, Virginia State University, USA.
Browne, M.; Allen, J.; Anderson, S.; Jackson, M. 2001. Overview of home deliveries in the $U K$, University of Westminster and Freight Transport Association (FTA), a study for the DTI.

Cairns, S. 1996. Delivering alternatives, Transport Policy 3(4): 155-176.

Campbell, A. M.; Savelsbergh, M. W. P. 2005. Decision Support for Consumer Direct Grocery Initiatives, Transportation Science 39(3): 313-327.

Campbell, A. M.; Savelsbergh, M. 2006. Incentive Schemes for Attended Home Delivery Services, Transportation Science 40(3): 327-341.

Carbone, V.; Roquet, A.; Roussat, C. 2017. The Rise of Crowd Logistics: A New Way to Co-Create Logistics Value, Journal of Business Logistics 38(4): 238-252.

Cárdenas, I.; Beckers, J.; Vanelslander, T. 2017. E-commerce last-mile in Belgium: Developing an external cost delivery index, Research in Transportation Business \& Management 24: 123-129.

Chen, Q.; Conway, A.; Cheng, J. 2017. Parking for residential delivery in New York City: regulations and behavior, Transport Policy 54: 53-60.

Chen, Y.; Yu, J.; Yang, S.; Wei, J. 2018. Consumer's intention to use self-service parcel delivery service in online retailing: An empirical study, Internet Research 28(2): 500-519.

Chopra, S. 2003. Designing the distribution network in a supply chain, Transportation Research Part E: Logistics and Transportation Review 39(2): 123-140.

Clarke, G.; Thompson, C.; Birkin, M. 2015. The emerging geography of e-commerce in British retailing, Regional Studies, Regional Science 2(1): 370-390.

Conway, A.; Fatisson, P.E.; Eickemeyer, P.; Cheng, J.; Peters, D. 2012. Urban micro-consolidation and last

\section{jjtte 68}


mile goods delivery by freight-tricycle in Manhattan: Opportunities and challenges. In Proceedings of the 91st Transportation Research Board Annual Meeting, 1-18.

Cristol, S.M.; Sealey, P. 2001. Simplicity Marketing: End Brand Complexity, Clutter, and Confusion, Marketing. Free Press, USA. 296 p.

Dablanc, L.; Morganti, E.; Arvidsson, N.; Woxenius, J.; Browne, M.; Saidi, N. 2017. The rise of on-demand "Instant Deliveries" in European cities, Supply Chain Forum: An International Journal 18(4): 203-217.

Daduna, J.R.; Lenz, B. 2005. Online-shopping and changes in mobility, In: Fleischmann, B.; Klose, A. (Eds.), Distribution Logistics: Advanced Solutions to Practical Problems. Springer, 65-84.

De Koster, M. B. M. 2002a. The logistics behind the enter click, In: Klose, A.; Van Wassenhove, L.N. (Eds.), Quantitative Approaches to Distribution Logistics and Supply Chain Management. Springer, Berlin, 131-148.

De Koster, M. B. M. 2002b. Distribution structures for food home shopping, International Journal of Physical Distribution \& Logistics Management 32(5): 362-380.

De Koster, M. B. M.; Neuteboom, A.J. 2001. The Logistics of Supermarket Chains, Elsevier, Doetinchem.

De Koster, M.B.M. 2003. Distribution strategies for online retailers, IEEE Transactions on Engineering Management 50(4): 448-457.

Devari, A.; Nikolaev, A. G.; He, Q. 2017. Crowdsourcing the last mile delivery of online orders by exploiting the social networks of retail store customers, Transportation Research Part E: Logistics and Transportation Review 105: 105-122.

DHL. 2014. Self-driving vehicles in logistics - a DHL perspective on implications and use cases for the logistics industry. DHL Customer Solution \& Innovation Troisdorf.
Durand, B.; Gonzalez-Feliu, J. 2012. Urban Logistics and E-Grocery: Have Proximity Delivery Services a Positive Impact on Shopping Trips? Procedia-Social and Behavioral Sciences 39: 510-520.

Edwards, J.; McKinnon, A.; Cullinane, S.L. 2009. Carbon Auditing the 'Last Mile': Modelling the Environmental Impacts of Conventional and Online Non-food Shopping, Green Logistics Report, HeriotWatt University.

Edwards, J.; McKinnon, A.; Cherrett, T.; McLeod, F.; Song, L. 2010. Carbon dioxide benefits of using collection-delivery points for failed home deliveries in the United Kingdom, Transportation Research Record 2191(1): 136-143.

eMarketer. 2019. Global Ecommerce 2019. Available from Internet: <https://www.emarketer.com/content/ global-ecommerce-2019>.

European Commission. 2019. Consumer Markets Scoreboard: Consumers at home in the Single Market - 2019 edition. Available from Internet: <https:// ec.europa.eu/info/sites/info/files/consumersconditions-scoreboard-2019_en_1.pdf $>$.

Fernie, J.; McKinnon, A.C. 2009. The development of e-tail logistics, In Fernie, J.; Sparks, L. (Ed.), Logistics and retail management: emerging issues and new challenges in the retail supply chain, 3rd ed, Kogan Page, 207-232.

Fernie, J.; Sparks, L. 2004. Retail Logistics: Changes and Challenges. In Fernie, J.; Sparks, L (Ed.), Logistics and Retail Management: Insights into Current Practice and Trends from Leading Experts, 2nd ed., Kogan Page, 3-37.

Fusco, G.; Tatarelli, L.; Valentini, M. 2003. Last-Mile, a Procedure to Set-Up an optimized Delivery Scheme. Logistics Systems for Sustainable Cities. In Proceedings of the 3rd International Conference on City Logistics, 147-161.

Gan, X.; Sethi, S. P.; Zhou, J. 2010. Commitmentpenalty contracts in drop-shipping supply chains with 
asymmetric demand information, European Journal of Operational Research 204(3): 449-462.

Gardrat, M.; Toilier, F.; Patier, D.; Routhier, J. 2016. How can the impact of new practices for supplying households be quantified in urban goods movements, In Proceedings of The 6th International Conference on Information Systems Logistics and Supply Chain, 1-9.

Gevaers, R.; Van de Voorde, E.; Vanelslander, T. 2009. Characteristics of innovations in last-mile logisticsusing best practices, case studies and making the link with green and sustainable logistics. In Proceedings of the European Transport Conference.

Gevaers, R.; Van de Voorde, E.; Vanelslander, T. 2014. Cost Modelling and Simulation of Last-mile Characteristics in an Innovative B2C Supply Chain Environment with Implications on Urban Areas and Cities, Procedia - Social and Behavioral Sciences 125: 398-411.

Ghajargar, M.; Zenezini, G.; Montanaro, T. 2016. Home delivery services: innovations and emerging needs, IFAC-PapersOnLine 49(12): 1371-1376.

Gould, J. 1998. Driven to Shop?: Role of Transportation in Future Home Shopping, Transportation Research Record 1617(1): 149-156.

Gould, J.; Golob, T.F. 1997. Shopping without travel or travel without shopping: An investigation of electronic home shopping, Transport Reviews 17(4): 355-376.

Hackney, R.; Grant, K.; Birtwistle, G. 2006. The UK Grocery Business: Towards a Sustainable Model for Virtual Markets, International Journal of Retail \& Distribution Management 34(4): 354-368.

Hausmann, L.; Herrmann, N.A.; Krause, J.; Netzer, T. 2014. Same-day delivery: The next evolutionary step in parcel logistics (McKinsey \& Company). Available from Internet: <https://www.mckinsey.com/ /media/ McKinsey/Industries/Travel\%20Transport $\% 20$
and\%20Logistics/Our\%20Insights/Same\%20day\%20 delivery\%20the\%20next\%20 evolutionary\%20step\%20 in\%20parcel\%20logistics/Sameday_delivery_The next_evolutionary_step_in_parcel_logistics.ashx $>$.

Hays, T.; Keskinocak, P.; De López, V. M. 2005. Strategies and challenges of internet grocery retailing logistics. In Geunes, J. (Ed.), Applications of Supply Chain Management and E-Commerce Research, Springer, 217-252.

Hobbs, J. E. 2020. Food supply chains during the COVID-19 pandemic, Canadian Journal of Agricultural Economics 68: 171-176.

Hoover, W. E.; Eloranta, E.; Holmström, J.; Huttunen, K. 2002. Managing the demand-supply chain: Value innovations for customer satisfaction. Wiley Inc, USA.

Hübner, A.; Kuhn, H.; Wollenburg, J. 2016. Last mile fulfilment and distribution in omni-channel grocery retailing, International Journal of Retail \& Distribution Management 44(3): 228-247.

IMRG. 2008. Valuing Home Delivery; E-retail Industry Review, IMRG, London.

IMRG. 2019. IMRG UK Consumer home delivery review 2018/2019. Available from Internet: <https:// www.imrg.org/uploads/media/default/0001/08/ 8 a 15d886a8799b236cb3b231b80262929c55a848. pdf?st>.

Iwan, S.; Kijewska, K.; Lemke, J. 2016. Analysis of Parcel Lockers' Efficiency as the Last Mile Delivery Solution - The Results of the Research in Poland, Transportation Research Procedia 12: 644-655.

Janz, O. 2001. Mehr Verkehr durch E-Commerce? Eine Analyse der Auswirkungen des E-CommerceWachstums (B2C) auf den Verkehr, Zeitschrijt for Verkehrswissenschaft 72: 48-69.

JDA Centiro. 2017. Customer pulse report 2017. European comparison: voice of the online European

\section{jitte 70}


shopper. Available from Internet: <http://now.jda.com/ rs/366-TWM-779/images/Customer\%20Pulse $\% 20$ $2017 \% 20$ European\%20Comparison.pdf $>$.

Joerss, M.; Schroder, J.; Neuhaus, F.; Klink, C.; Mann, F. 2016. Parcel delivery: the future of last mile, McKinsey\&Company (Travel, Transport and Logistics).

Kämäräinen, V.; Punakivi, M. 2002. Developing Costeffective Operations for the e-Grocery Supply Chain, International Journal of Logistics Research and Applications 5(3): 285-298.

Kämäräinen, V.; Punakivi, M. 2004. Unattended reception - a business opportunity? International Journal of Services Technology and Management 5(2): 206-220.

Kämäräinen, V.; Saranen, J.; Holmström, J. 2001a. The reception box impact on home delivery efficiency in the e-grocery business, International Journal of Physical Distribution \& Logistics Management 31(6): 414-426.

Kämäräinen, V.; Småros, J.; Holmström, J.; Jaakola, T. 2001b. Cost-effectiveness in the e-grocery business, International Journal of Retail \& Distribution Management 29 (1): 41-48.

Kim, S.; Park, D.; Kim, S.; Park, H. 2014. Modeling Courier Vehicles' Travel Behavior, Transportation Research Record: Journal of the Transportation Research Board 2410(1): 67-75.

Langley, C. J. 2019. Third-party Logistics Study: The State of Logistics Outsourcing: Results and Findings of the 23th Annual Study, Infosys Consulting, Penske, Korn Ferr, Penn State Smeal College of Business. Available from Internet: <https://www.kornferry.com/ content/dam/kornferry/docs/article-migration//20193PL-Study.pdf $>$.

Lee, H. L.; Whang, S. 2001. Winning the Last Mile of E-Commerce, MIT Sloan Management Review 42(4): 54-62.
Lim, S. F. W. T.; Jin, X.; Srai, J. S. 2018. Consumer-driven e-commerce, International Journal of Physical Distribution \& Logistics Management 48(3): 308-332.

Lunce, S. E.; Lunce, L. M.; Kawai, J.; Maniam, B. 2006. Success and Failure of Pure-Play Organizations: Webvan Versus Peapod, a Comparative Analysis, Industrial Management and Data Systems 106(9): 1344-1358.

Ma, S.; Jemai, Z.; Sahin, E.; Dallery, Y. 2017. The news-vendor problem with drop-shipping and resalable returns, International Journal of Production Research 55(22): 6547-6571.

McKinnon, A. C.; Tallam, D. 2003. Unattended delivery to the home: an assessment of the security implications, International Journal of Retail \& Distribution Management 31(1): 30-41.

McLeod, F.; Cherrett, T.; Song, L. 2006. Transport impacts of local collection/delivery points, International Journal of Logistics Research and Applications 9(3): 307-317.

Mehmann, J.; Frehe, V.; Teuteberg, F. 2015. Crowd Logistics - A Literature Review and Maturity Model, In Proceedings of the Hamburg International Conference of Logistics (HICL), 117-145.

Merz, M. 2002. E-Commerce und E-Business-Marktmodelle, Anwendungen und Technologien. 2. Ed., Heidelberg.

Morganosky, M. A.; Cude, B. J. 2000. Consumer response to online grocery shopping, International Journal of Retail \& Distribution Management 28(1): 17-26.

Morganti, E.; Dablanc, L.; Fortin, F. 2014a. Final deliveries for online shopping: The deployment of pickup point networks in urban and suburban areas, Research in Transportation Business \& Management 11: 23-31.

Morganti, E.; Seidel, S.; Blanquart, C.; Dablanc, L.; Lenz, B. 2014b. The impact of e-commerce on final deliveries: alternative parcel delivery services in France and Germany, Transportation Research Procedia 4: 178-190. 
Mukhopadhyay, S. K.; Setoputro, R. 2004. Reverse logistics in e-business, International Journal of Physical Distribution \& Logistics Management 34(1): 70-89.

Murphy, A. J. 2003. (Re)solving space and time: Fulfilment issues in online grocery retailing, Environment and Planning A 35(7): 1173-1200.

Murphy, A.J. 2007. Grounding the Virtual: The Material Effects of Electronic Grocery Shopping, Geoforum 38(5): 941-953.

Netessine, S.; Rudi, N. 2006. Supply chain choice on the Internet, Management Science 52(6): 844-864.

Oldhager, J. 2003. Strategic positioning of the order penetration point, International Journal of Production Economics 83(3): 319-329.

Ozbaygin, G.; Karasan, O. E.; Savelsbergh, M.; Yaman, H. 2017. A branch-and-price algorithm for the vehicle routing problem with roaming delivery locations, Transportation Research Part B: Methodological 100: 115-137.

Pan, S.; Chen, C.; Zhong, R. Y. 2015. A crowdsourcing solution to collect e-commerce reverse flows in metropolitan areas, IFAC-PapersOnLine 48(3): 19841989.

Park, H.; Park, D.; Jeong, I.J. 2016. An effects analysis of logistics collaboration in last-mile networks for CEP delivery services, Transport Policy 50: 115-125.

Piplani, R.; Saraswat, A. 2012. Robust optimisation approach to the design of service networks for reverse logistics, International Journal of Production Research 50(5): 1424-1437.

Punakivi, M. 2003. Comparing alternative home delivery models for e-grocery business. PhD thesis, Helsinki University of Technology, Industrial Engineering and Management, Helsinki.
Punakivi, M.; Saranen, J. 2001. Identifying the success factors in e-grocery home delivery, International Journal of Retail \& Distribution Management 29(4): 156-163.

Punakivi, M.; Tanskanen, K. 2002. Increasing the cost efficiency of e-fulfilment using shared reception boxes, International Journal of Retail \& Distribution Management 30(10): 498-507.

Punakivi, M.; Yrjölä, H.; Holmström, J. 2001. Solving the last mile issue: reception box or delivery box, International Journal of Physical Distribution \& Logistics Management 31(6): 427-439.

Reyes, D.; Savelsbergh, M.; Toriello, A. 2017. Vehicle routing with roaming delivery locations, Transportation Research Part C: Emerging Technologies 80: 71-91.

Slabinac, M. 2016. Innovative solutions for a "last-mile" delivery-a European experience. In Proceedings of the $15^{\text {th }}$ International Scientific Conference Business Logistics in Modern Management, 111-129.

Småros, J.; Holmström, J. 2000. Viewpoint: reaching the consumer through e-grocery VMI, International Journal of Retail \& Distribution Management 28(2): 55-61.

Tadić, S.; Veljović, M. 2020a. Logistics flows of household, Tehnika 75(2): 225-237.

Tadić, S.; Veljović, M. 2020b. Logistics of rural tourism, International Journal for Transport and Traffic Engineering 10(3): 323-350.

Tadić, S.; Veljović, M. 2020c. Return flows in home delivery. In Proceedings of the $19^{\text {th }}$ International Conference on Transport Science (ICTS), Portoroz, Slovenia, 340-346.

Tadić, S.; Veljović, M. 2020d. Home delivery: concept and characteristics, International Journal for Traffic and Transport Engineering 10(4): 519-533. 
Tadić, S.; Zečević, S.; Kostadinović, A. 2017. Home delivery - problems and opportunities. In Proceedings of the $6^{\text {th }}$ international conference Towards a Humane City: Smart Mobility - Synergy Between Sustainable Mobility and New Technologies, Faculty of technical sciences, University of Novi Sad, Novi Sad, Serbia, 131-136.

Tadić, S.; Zečević, S. 2015a. Cooperation and consolidation of flows in city logistics, Tehnika 70(4): 687-694.

Tadić, S.; Zečević, S. 2015b. Integrated planning aimed at sustainability city logistics solutions [in Serbian: Integrisano planiranje sa ciljem održivosti city logističkih rešenja], Tehnika 70(1): 164-173.

Tadić, S.; Zečević, S. 2016. Modeling of city logistics concepts [in Serbian: Modeliranje koncepcija city logistike], Faculty of Transport and Traffic Engineering, University of Belgrade, Serbia, 358 p.

Tadić, S.; Zečević, S.; Krstić, M. 2014a. City logistics initiatives aimed at improving sustainability within existing context of urban area [in Serbian: Inicijative city logistike u cilju poboljšanja održivosti unutar postojećeg konteksta urbane sredine], Tehnika 61(3): 487-495.

Tadić, S.; Zečević, S.; Krstić, M. 2014b. A novel hybrid MCDM model based on fuzzy DEMATEL, fuzzy ANP and fuzzy VIKOR for city logistics concept selection, Expert Systems with Applications 41(18): 8112-8128.

Tadić, S.; Zečević, S.; Krstić, M. 2015. City logistics - status and trends, International Journal for Traffic and Transport Engineering 5(3): 319-343.

Taniguchi, E.; Thompson, R.G.; Yamada, T. 2003. Predicting the effects of city logistics schemes, Transport Reviews 23(4): 489-515.

Tanskanen, K.; Yrjölä, H.; Holmström, J. 2002. The Way to Profitable Internet Grocery Retailing - Six Lessons Learned, International Journal of Retail \& Distribution Management 30(2): 169-178.
Van Duin, J. H. R.; De Goffau, W.; Wiegmans, B.; Tavasszy, L. A.; Saes, M. 2016. Improving Home Delivery Efficiency by Using Principles of Address Intelligence for B2C Deliveries, Transportation Research Procedia 12: 14-25.

Vanelslander, T.; Deketele, L.; Van Hove, D. 2013. Commonly used e-commerce supply chains for fast moving consumer goods: comparison and suggestions for improvement, International Journal of Logistics Research and Applications 16(3): 243-256.

Visser, J.; Nemoto, T. 2003. E-commerce and the consequences for freight transport. Innovations in freight transport. WIT Press, Boston.

Visser, J.; Nemoto, T.; Browne, M. 2014. Home Delivery and the Impacts on Urban Freight Transport: A Review, Procedia - Social and Behavioral Sciences 125: 15-27.

Wang, X.; Zhan, L.; Ruan, J.; Zhang, J. 2014. How to Choose "Last Mile" Delivery Modes for E-Fulfillment, Mathematical Problems in Engineering 2014: 1-11.

Wang, Y.; Zhang, D.; Liu, Q.; Shen, F.; Lee, L. H. 2016. Towards enhancing the last-mile delivery: An effective crowd-tasking model with scalable solutions, Transportation Research Part E: Logistics and Transportation Review 93: 279-293.

Weltevreden, J. W. J. 2008. B2C e-commerce logistics: the rise of collection-and-delivery points in The Netherlands, International Journal of Retail \& Distribution Management 36(8): 638-660.

Weltevreden, J. W.J.; Rotem-Mindali, O. 2009. Mobility effects of B2C and C2C e-commerce in the Netherlands: a quantitative assessment, Journal of Transport Geography 17(2): 83-92.

Winkenbach, M.; Janjevic, M. 2018. Classification of Last-Mile Delivery Models for e-Commerce Distribution: A Global Perspective, City Logistics 1: 209-229. 
Xing, Y.; Grant, D. B. 2006. Developing a framework for measuring physical distribution service quality of multi-channel and "pure player" internet retailers, International Journal of Retail \& Distribution Management 34(4/5): 278-289.

Xu, M.; Ferrand, B.; Roberts, M. 2008. The last mile of e-commerce - unattended delivery from the consumers and eTailers' perspectives, International Journal of Electronic Marketing and Retailing 2(1): 20-37.

Yaman, H.; Karasan, O. E.; Kara, B. Y. 2012. Release Time Scheduling and Hub Location for Next-Day Delivery, Operations Research 60(4): 906-917.

Yrjölä, H. 2001. Physical distribution considerations for electronic grocery shopping, International Journal of Physical Distribution \& Logistics Management 31(10): 746-761.
Yuen, K. F.; Wang, X.; Ng, L. T. W.; Wong, Y. D. 2018. An investigation of customers' intention to use selfcollection services for last-mile delivery, Transport Policy 66: $1-8$.

Zečević, S.; Tadić, S. 2006. City logistics [in Serbian: City logistika], Faculty of Transport and Traffic Engineering, University of Belgrade, Serbia, 190 p.

Zhou, M.; Zhao, L.; Kong, N.; Campy, K. S.; Xu, G.; Zhu, G.; Cao, X.; Wang, S. 2020. Understanding consumers' behavior to adopt self-service parcel services for lastmile delivery, Journal of Retailing and Consumer Services 52: 101911.

\section{jitte 74}

